3 Impact of dietary fiber and fat on gut microbiota re-modeling

\title{
and metabolic health
}

5

6 Alfonso Benítez-Páez ${ }^{1 *}$, Eva M. Gómez Del Pulgar ${ }^{1}$, Louise Kjølbæk ${ }^{2}$, Lena Kirchner

Brahe $^{2}$, Arne Astrup ${ }^{2}$, LesliHingstrup Larsen ${ }^{2}$,Yolanda Sanz ${ }^{1}$

8

9

10 Affiliations:

$11{ }^{1}$ Microbial Ecology, Nutrition \& Health Research Unit. Institute of Agrochemistry and 12 Food Technology (IATA-CSIC). 46980 Paterna-Valencia, Spain.

$13{ }^{2}$ Department of Nutrition, Exercise and Sports (NEXS). Faculty of Science. University of 14 Copenhagen. 1958 Frederiksberg, Denmark.

15

16

17 *Corresponding author: Av. Catedratic Agustin Escardino, 7. 46980 Paterna-Valencia, 18 Spain. Tel: +34 963900022 ext 2131. E-mail: abenitez@iata.csic.es.

19 


\section{Abstract}

21 Background. Scientific evidence suggests that diet plays a role in obesity and its comorbidities, partly via its interactions with the individual's gut microbiota. Likewise, the individual's microbiota influences the efficacy of dietary interventions to reduce body weight. However, we require a better understanding of the key components of the gut microbiota that are responsive to specific diets and of their effects on energy balance in order to use this information in practice.

Scope and Approach. This review provides an up-to-date description of the influence of dietary fibers and fat on gut microbiota and the mechanisms presumably mediating their effects on metabolic health. We also discuss the main knowledge gaps and the need to gain greater understanding of the role of diet-microbe interactions in obesity and the associated comorbidities.

Key Findings and Conclusions. Dietary fibers are major drivers of gut microbiota composition and function, stimulating the dominance of bacteria able to utilize these substrates as energy source, although effects vary depending on both the type of fiber and the individual's microbiota. However, the key bacteria and the primary and secondary metabolic pathways mediating specific fiber-induced effects on the metabolic phenotype remain unclear, and this information is necessary to personalize fiber-based interventions. The literature also shows that gut microbiota contributes to the adverse consequences of high-fat diets on the metabolic phenotype; however, little is known about the effects of dietary fat type. Further progress is expected from translational approaches integrating controlled dietary intervention human trials, combining functional omics technologies and physiological/clinical endpoints, and mechanistic studies in experimental models. This will 
43 ultimately help us to progress towards establishing informed microbiome-based dietary

44 recommendations and interventions, which can contribute to tackling the obesity epidemic 45 and its comorbidities.

46 Key words: Gut microbiota, microbiome, fiber, fat, diet-related diseases, obesity. 47 


\section{Introduction}

49 Obesity has reached pandemic dimensions affecting a vast number of people worldwide. In 502014 , approximately $39 \%$ of adults (1.9 billion) were overweight and $13 \%$ of these (600 51 million) were obese. Moreover, 42 million children under the age of 5 were reported as 52 overweight or obese in 2013(World Health Organization, 2015). It is well known that obesity is not only associated with populations in high-income countries, but the prevalence is continuously growing in low- and mid-income countries, particularly in urban settings (World Health Organization, 2015). Obesity is a result of an unbalance between energy intake and expenditure, to which over-nutrition and a sedentary lifestyle are major contributors (Coppinger, Jeanes, Dabinett, Vogele, \& Reeves, 2010). Obesity is associated with a state of chronic low-grade inflammation, which partly explains the insulin resistance phenotype observed in many obese individuals. In turn, insulin resistance is a component of the metabolic syndrome that often precedes the development of type 2 diabetes (T2D) and cardiovascular disease (CVD) (Jia, DeMarco, \& Sowers, 2016). This metabolic inflammation is characterized by infiltration of macrophages and lymphocytes in peripheral tissues. This is accompanied by an increased production of pro-inflammatory cytokines, adipokines, acute-phase proteins and other immune mediators as a consequence of the activation of several signalling pathways, including the nuclear factor kappa B $(\mathrm{NF \kappa B}) /$ Inhibitor of the kinase (IKK), c-jun N-terminal kinase (JNK), protein kinase $\mathrm{R}$ (PKR) and theToll-Like receptors (TLRs) (Gregor \& Hotamisligil, 2011). Adipose tissue from obese individuals is considered to be the main contributor to obesity-related metabolic inflammation, with the highest accumulation of infiltrating macrophages and tissue 
concentrations of cytokines, with similar events occurring in the liver and central nervous system, contributing to systemic insulin resistance (Johnson \& Olefsky, 2013).

In the last decade, an increasing number of studies have reported that obesity is associated with alterations in gut microbiota structure, suggesting that specific microbial taxa could be contributing factors to the obesity epidemic, although results are not fully consistent across human observational studies (Sanz, Rastmanesh, \& Agostoni, 2013). Animal studies have provided information about the mechanisms by which gut microbiota could play a role in obesity, including contribution to nutrient digestion and absorption and to regulation of immune and neuro-endocrine functions (Moya-Perez, Neef, \& Sanz, 2015). Experimental models have also demonstrated that gut microbiota can transmit the obesity-associated metabolic phenotype of its original human host when transferred to a germ-free recipient, providing a first evidence of causality (Turnbaugh, et al., 2006). Furthermore, a unique fecal transplantation study in humans has also demonstrated that the transference of feces from a lean donor into subjects with metabolic syndrome beneficially influence glucose metabolism, confirming the causal role of gut microbiota (Vrieze, et al., 2010). Nonetheless, the role of gut microbiota in obesity seems largely dependent on diet-microbe interactions due to the fact that diet is a major modifiable factor influencing gut microbiota composition and function (De Filippis, et al., 2015; Flint, Duncan, Scott, \& Louis, 2015). Indeed, experimental models revealed that such interactions contribute to obesity, for example, by increasing lipid absorption or aggravating adipose tissue inflammation independently of adiposity in the context of diets rich in saturated lipids (Caesar, Tremaroli, Kovatcheva-Datchary, Cani, \& Backhed, 2015; Semova, et al., 2012). Furthermore, dietary reprograming of microbiota ameliorates development of metabolic dysfunction despite susceptible genotypes (Ussar, et al., 2015). Nevertheless, our understanding of how diet- 
microbe interactions influence energy balance, eating behavior and obesity in humans is still insufficient to transform this information into practical solutions to tackle obesityassociated disorders.

This review discusses the most recent data regarding the potential role of dietary fiber and fat in remodeling gut microbiota composition and function and, thereby, in programming metabolic health. It also addresses the main limitations that must be overcome to progress our understanding of the microbiome's role in the chain of events causing obesity. Only on gaining a better understanding of the above, will we be able to speed up the translation of this information into informed microbiome-based dietary interventions and recommendations.

\section{Impact of dietary fiber on human physiology}

\subsection{Dietary fiber: role in metabolic health and as main fuel for gut microbiota.}

Dietary fiber is generally defined as non-digestible carbohydrates plus lignin, which include structurally different components including non-starch polysaccharides, resistant oligosaccharides (e.g. fructo-oligosaccharides [FOS], galacto-oligosaccharides [GOS]) and resistant starch (EFSA NDA Panel, 2010). Prebiotics are defined as dietary fibers that modify the composition and/or metabolic activity of gut microbiota, thereby conferring a benefit to the host (G. R. Gibson, 2004; G. R. Gibson, Probert, Loo, Rastall, \& Roberfroid, 2004). According to this definition, a wide variety of food ingredients can be classified as prebiotics such as GOS, FOS and longer inulin-derived fructans, xylo-oligosaccharides (XOS) and arabinoxylan oligosaccharides (AXOS); however this is based mainly on their impact on gut microbiota rather than on robust evidence of their effects on health-related 
118 endpoints (Hutkins, et al., 2016). Dietary fiber is not digested by human enzymes and thus

119 it reaches proximal colonic regions, where it constitutes the main energy source for obligate

120 anaerobic bacteria, whose fermentative activity leads to the generation of organic acids

121 (lactic, succinic acid) and short-chain fatty acids (SCFA) (acetate, propionate and butyrate).

122 Consequently, the quantity and quality of fiber is considered to be one of the main dietary

123 determinants of gut microbiota composition and function (Scott, Gratz, Sheridan, Flint, \&

124 Duncan, 2013). The current recommendations on dietary fiber intake (25 g per day for

125 adults) are based on their well-known role in regulating bowel habits (frequency of

126 defecation), including native chicory inulin considered to be prebiotic (Hutkins, et al.,

127 2016). In addition, there is evidence for a role of dietary fiber and some prebiotics (inulin

128 and oligofructose) in the reduction of dietary glycemic responses and glycemic load, with

129 favorable effects on metabolic risk factors. Furthermore, consumption of fiber-rich diets

130 with fiber intake above recommendations is associated with a reduced risk of coronary

131 heart disease and type 2 diabetes as well as improved weight maintenance (Bes-Rastrollo,

132 Martinez-Gonzalez, Sanchez-Villegas, de la Fuente Arrillaga, \& Martinez, 2006; EFSA

133 NDA Panel, 2010; S. Liu, et al., 2000; Ludwig, et al., 1999; Ye, Chacko, Chou, Kugizaki,

$134 \&$ Liu, 2012). Dietary fiber is thought to positively influence metabolic health through

135 multiple mechanisms, although effects cannot be generalized as they vary depending on the

136 type of fiber. The mechanisms of action include direct effects related to its physicochemical

137 and structural properties (e.g. indigestibility, viscosity, etc.) and indirect effects mediated

138 by the individual's gut microbiota. For example, compared to digestible carbohydrates,

139 insoluble and soluble fibers reach distal portion of colon with no major degradation by

140 human enzymes leading to a significant reduction in postprandial glycemic responses due

141 to their slower digestion (EFSA, 2014). Consequently, consumption of fiber improves the 
142 glucose metabolism as a whole, which have direct impact on satiety and tip the balance

143 towards oxidation instead storage metabolism (reviewed in (Koh-Banerjee \& Rimm,

144 2003)). Moreover, dietary fiber is considered to be very useful for weight loss/maintenance

145 aims given its low energetics estimated to be $\sim 1.91 \mathrm{kcal} / \mathrm{g}(8 \mathrm{~kJ} / \mathrm{g})$ in comparison with other

146 macronutrients as digestible carbohydrates, $(\sim 4.06 \mathrm{kcal} / \mathrm{g})$, proteins $(\sim 4.06 \mathrm{kcal} / \mathrm{g})$, and fat

147 ( $\sim 8.84 \mathrm{kcal} / \mathrm{g})$ (Menezes, et al., 2016). Soluble viscous fibers may also exert beneficial

148 metabolic effects by their ability to form gels that delay gastric emptying, inhibit nutrient

149 absorption and bile acid (BA) binding; altogether this may contribute to a decreased

150 postprandial glycemic response and a reduction in body cholesterol stores due to increased

151 synthesis of new BAs from cholesterol in the liver (Dikeman \& Fahey, 2006). In addition,

152 dietary fiber is thought to mediate other effects (e.g. satiety and anti-inflammatory effects)

153 through activation of the fermentative activity of gut bacteria, and the generation of

154 potentially beneficial metabolites (e.g. SCFAs), as explained in greater detail in section 3.

155

156 1.2. Evidence of the influence of dietary fiber on gut microbiota from observational studies.

157 The role of non-digestible carbohydrates in the gut microbiota is well exemplified by the

158 differences in the infant's gut microbiota between breast-fed and formula-fed infants and

159 between infant formula supplemented or not with oligosaccharides, which mainly stimulate

160 the growth of bifidobacteria (Closa-Monasterolo, et al., 2013; Hascoet, et al., 2011). These

161 effects have also been well-established by comparing the gut microbiota of individuals

162 from different geographical regions that consume rural diets (Africa and South America)

163 rich in dietary fiber or Western diets (Europe and North America) rich in animal protein

164 and fat(De Filippo, et al., 2010; Yatsunenko, et al., 2012). Acomparison of the microbiota

165 between European and African children, consuming a fiber-rich diet, showed that the latter 
166 have reduced abundance of Firmicutes and increased abundance of Bacteroidetes,

167 particularly the Prevotella and Xylanibacter genera, known to have genes specialized in 168 cellulose and xylan utilization, with parallel increased fecal concentrations of SCFAs. In 169 contrast, Enterobacteriaceae species (Proteobacteria) were reduced in African compared 170 with European children (De Filippo, et al., 2010). Another large study including healthy

171 children and adults also revealed important differences in bacterial communities and 172 functional gene repertoires between US subjects from metropolitan areas and those from 173 countries with a rural lifestyle (Amazonas of Venezuela and Malawi), finding the genus 174 Prevotella to be abundant in humans with a diet rich in corn and cassava and in US children 175 not following a full western diet (Yatsunenko, et al., 2012). A more recent study comparing 176 African Americans and rural South Africans, found that animal protein and fat intake was 177 2-3 times higher in Americans whereas carbohydrate and fiber (mainly resistant starch) 178 intake was higher in Africans. The same authors also reported diet-associated microbiota 179 and metabolite changes that were related to colon cancer risk. While the American 180 microbiota was dominated by Bacteroides, the African microbiota was dominated by 181 Prevotella and higher levels of starch degraders, carbohydrate fermenters, and butyrate 182 producers. Moreover, the American microbiota had higher levels of potentially pathogenic 183 Proteobacteria (Escherichia and Acinetobacter) and BA deconjugators (Ou, et al., 2013). A 184 recent Dutch population-based metagenomic study involving 1,135 subjects has associated 185 higher diversity, functional microbiome richness and abundance of Bacteroidetes with 186 higher intake of fruits and vegetables (source of dietary fiber), higher concentrations of 187 high-density lipoprotein (HDL) and lower concentrations of fecal chromogranin A 188 (Zhernakova, et al., 2016). The total amount of carbohydrates in the diet was also 189 positively associated with Bifidobacterium but negatively associated with Lactobacillus and 
microbiome diversity (Zhernakova, et al., 2016). All in all, these observational studies

191 reveal that long-term consumption of fiber-rich diets promotes the dominance of fiber-

192 degraders of the phylum Bacteroidetes and Actinobacteria (Bifidobacteriumspp.) and, more

193

194

195

196

197

198

199

200 consistently, of Prevotella spp. and reductions in Proteobacteria; nevertheless, Bacteroides spp. seem to be adapted to both fiber-rich diets and diets rich in animal protein and fat, probably due to their versatile metabolic capabilities. Notwithstanding, these observational data only provide associations but not causal relationships between specific dietary habits and the predominance of specific bacterial taxa, which limits their value in practice. Furthermore, other relevant environmental factors such as hygiene, geography, and ethnicity that could be involved in the respective gut microbiota profile observed are not well assessed.

A recent experimental study in animal models also suggests that the lack of dietary fiber leads to a substantial loss in gut microbiota diversity, which influences the ability of gut bacteria to be transferred from parents to offspring. It also revealed that simply restoring fiber consumption was not enough to reverse these effects since some bacterial groups failed to return to their previous levels (Sonnenburg, et al., 2016). These results have led to hypothesize that long-term dietary changes in industrialized countries could have altered the host-microbiota partnership and microbiome functionality, with an adverse long-term impact on health that could be transmitted from generation to generation (Sonnenburg, et al., 2016). Notwithstanding, evidence from systematic studies in humans is required to confirm this hypothesis. 
213 A summary is given in Table 1 of recent representative human dietary interventions 214 investigating how most common types of dietary fibers contribute to remodeling the gut 215 microbiota. The responsiveness and effects of dietary fibers may differ depending on the 216 individual's gut microbiota profile (Korpela, et al., 2014), suggesting the need to work 217 towards defining more specific and personalized dietary interventions and 218 recommendations.

1.3.1. Effects of wholegrain (WG)-rich foods. Wholegrain cereals are composed of starch221 rich endosperm, germ, and bran with high plant-fiber content. During harvesting and food 222 processing, these components must preserve their relative proportions as in the intact kernel 223 (HEALTHGRAIN Consortium - http://www.healthgrain.org). Rice, wheat, maize, oats, and 224 barley are the main whole grains consumed worldwide and some of them have been proven 225 to reduce the risk of certain diet-related diseases such as obesity and CVD. A controlled 226 cross-over study showeda bifidogenic effectupon consumption of $48 \mathrm{~g} /$ day maize-based 227 WG breakfast cereals during 21 days (Carvalho-Wells, et al., 2010). This effect was 228 observed exclusively for the intervention period and not sustained after completion of the 229 WG diet, strongly indicating that WG fiber is predominantly used by Bifidobacterium spp. 230 (Carvalho-Wells, et al., 2010). Similar results were obtained by Costabile and coworkers 231 who reported increased bifidobacteria and lactobacilli in feces after daily consumption of 232 WG wheat breakfast cereals (48 g/day) in comparison with non-WG cereal (Costabile, et 233 al., 2008). More recent results have shown that a four-week dietary intervention with 60 234 g/day WG barley flakes in healthy adults induced a significant increase in the genus Blautia 235 and a less pronounced increase in the abundance of the genera Roseburia, Bifidobacterium 236 and Dialister (Martinez, et al., 2013). Additionally, this study showed that WG barley, 
brown rice and specially the combination of WG barley and brown rice reduced plasma 238 interleukin-6 (IL-6) and postprandial glucose. Interestingly, Eubacterium rectale was 239 significantly more abundant in volunteers showing improvements in postprandial blood 240 glucose and insulin response, whereas abundance of Dialister species was associated with 241 the highest improvements in IL-6 levels (Martinez, et al., 2013).

1.3.2. Resistant starch (RS). Starch is the major component of the plant-derived foods and comprises an important part of the human diet. The starch is referred as resistant when it cannot be hydrolyzed by digestive enzymes of the human GIT. The RS can be classified into several types (RS1 to RS5) according to the physical or chemical reasons to be indigestible. The RS1 is contained inside whole grains and is physically inaccessible for digestion; the RS2 is also native starch but remains indigestible by its compact structure; the RS3, also known as retrograde starch, is obtained by slow re-crystallization prior to heat disruption on water; the RS4 is the chemically modified starch by cross-linking or esterification; and the RS5 is a mixture of starch with lipids with high stability (Ma \& Boye, 2016). Early studies about the RS impact on gut microbiota indicated that administration of controlled diet including $22 \mathrm{~g} /$ day $\mathrm{RS}$ induces changes in gut microbiota mainly in the clostridia cluster including members of the Ruminococcus genus (Abell,

255 Cooke, Bennett, Conlon, \& McOrist, 2008). Interventions with 50-60 g/day RS3 increased 256 the abundance of several Ruminococcus spp. and especially Ruminococcus bromii and 257 Eubacterium rectale (Walker, et al., 2011). Similar results were obtained when $33 \mathrm{~g} /$ day 258 RS2 or RS4 were administrated in baked crakers to volunteers during 3 weeks. In this case, 259 increased proportions of Bifidobacterium adolescentis and Parabacteroides distasonis were 260 found to be induced particularly by RS4 intake, whereas increased proportions of 
261 Ruminococcus bromii and Eubacterium rectale were induced by RS2 consumption 262 (Martinez, Kim, Duffy, Schlegel, \& Walter, 2010). In addition, RS intake of has been found 263 to improve lipid metabolism in individuals with metabolic syndrome and help to control 264 waist circumference and fat mass in non metabolic syndrome individuals (Nichenametla, et 265 al., 2014). These beneficial effects of RS on metabolic aspects are thought to be at least 266 partially mediated by the microbiota induced changes but direct evidence still has to be 267 provided.

268 1.3.3. Inulin and FOS. Inulin and FOS, also called oligofructose or oligofructans, are types 269 of fructo-polysaccharides that consist of several $\beta$-linked D-fructosyl residues with a D270 glucose group at end of the extended saccharide chain. These differ in the polymerization 271 degree, which may range from 2 to 60 fructose units. FOS are usually produced by 272 degradation of inulin obtained primarily from artichoke and chicory plants. These are used 273 in the food industry as sweeteners, texture modifiers and fibers. A number of intervention 274 studies have shown that the effects of inulin and FOS on gut microbiota composition can be 275 associated with modifications on health related outcomes or subrogated biomarkers (Table 276 1). In adults and infants, it is generally reported that inulin and FOS intake increases the 277 number of bifidobacteria, sometimes associated with changes in metabolic products (e.g. 278 lactate) (Closa-Monasterolo, et al., 2013; Garcia-Peris, et al., 2012; Petry, Egli, Chassard, 279 Lacroix, \& Hurrell, 2012). In some studies, inulin or FOS-induced microbiota changes have 280 also been correlated with indicators of metabolic health. For example, a three-month 281 double-blind placebo-controlled intervention with a mixture ofinulin/oligofructose or 282 maltodextrin ( $8 \mathrm{~g}$ twice daily in powder to be dissolved in warm drinks) in obese women, 283 showed increased abundances of Bifidobacterium spp. and Faecalibacterium prausnitzii, 
284 which correlated to reduced serum LPS (lipopolysacchraide) levels. Additionally, the 285 researchers observed reductions of Bacteroides intestinalis, Bacteroides vulgatus and 286 Propionibacterium spp., which correlated to modest changes in fat mass. Additionally, they 287 found reductions in plasma LPS, fecal acetate and propionate concentrations, and fasting 288 insulinemia (Dewulf, et al., 2013; Salazar, et al., 2015). A recent study has evaluated the 289 role of agave inulin showing a dose-dependent bifidogenic effect. The consumption of 5 or $2907.5 \mathrm{~g} /$ day agave inulin in chocolate chews, primarily promoted the presence of $B$. 291 adolescentis, B. breve, B. longum, and B. pseudolongum (Holscher, et al., 2015). Positive 292 correlations were also detected between fecal butyrate concentrations and the dose of fiber, 293 and between fecal butyrate concentration and Faecalibacterium abundance. These effects 294 could be explained by cross-feeding interactions disclosed between bifidobacteria and 295 Faecalibacterium (Moens, Weckx, \& De Vuyst, 2016). Interestingly, a depletion of 296 Desulfovibrio species was also identified as a consequence of agave inulin consumption 297 (Holscher, et al., 2015), which could be of clinical relevance because increased 298 Desulfovibrio species have been related to obesity and the associated endotoxemia (Xiao, et 299 al., 2014; Zhang-Sun, Augusto, Zhao, \& Caroff, 2015; Zhang, et al., 2009).

302 GOS are mainly produced through transgalactosylation reactions mediated by $\beta$ 303 galactosidases using lactose or derivatives as substrate. GOS are often used to supplement 304 infant formula due to their chemical and structural resemblance to human milk 305 oligosaccharides. In infant formula, GOS have been shown to exert a bifidogenic effect 306 (Giovannini, et al., 2014). In adults, the six-week administration of $5.5 \mathrm{~g} /$ day GOS powder 
307 mixture dissolved in water to subjects with metabolic syndrome has been shown to reduce

308 levels of Clostridium histolyticum, Desulfovibrio spp. and Bacteroides spp.(Vulevic, Juric, 309 Tzortzis, \& Gibson, 2013). These changes were accompanied by increases in 310 Bifidobacterium spp. and reductions in inflammatory markers, including fecal calprotectin 311 and plasma C-reactive protein (CRP) and in some metabolic parameters (e.g. plasma 312 insulin, total cholesterol and triglycerides in males).

314 1.3.5. Xylans and arabinoxylans. Arabinoxylans (AX) from cereals are cell wall 315 components that constitute a major part of the dietary fiber fraction of cereal grains and 316 thus, an important fiber source in the diet (McCleary, 2003). Enzymatic hydrolysis of AX 317 either in the production of processed foods or by bacteria in the colon yields 318 arabinoxylanoligosaccharides (AXOS) and xylooligosaccharides (XOS), both of which are 319 proposed to be prebiotic fibers (Broekaert, et al., 2011). Additionally to the well known 320 bifidogenic effect of AX, a fact in which is based its prebiotic potential (reviewed in 321 (Riviere, Selak, Lantin, Leroy, \& De Vuyst, 2016)), other AX-degrading bacteria in the 322 human colon belong to the genera Roseburia and Bacteroides and include the butyrate 323 producing Roseburia intestinalis (Chassard, Goumy, Leclerc, Del'homme, \& Bernalier324 Donadille, 2007). These data are of interest since a higher relative abundance of butyrate325 producing bacteria and Bacteroides spp. has been reported in healthy individuals compared 326 to patients with T2D or pre-diabetic subjects in some studies (reviewed in (Sanz, Olivares, 327 Moya-Perez, \& Agostoni, 2015)). Human intervention trials have also shown increased 328 fecal abundance of Bifidobacterium spp. following intake of $4 \mathrm{~g} /$ day XOS during three 329 weeks (Chung, Hsu, Ko, \& Chan, 2007) and from 2.14 to $10 \mathrm{~g}$ /day AXOS (Cloetens, et al., 330 2010; Francois, et al., 2012; Maki, et al., 2012). Furthermore, a higher abundance of this 
331 genus has been reported in normal weight subjects compared to obese and T2D subjects in 332 some observational studies (Schwiertz, et al., 2010; Wu, et al., 2010).

\section{Microbiome components involved in the utilization of dietary fiber}

335 Dietary intake of fibers may lead to enrichment and altered expression of microbial genes

336 which encode proteins/enzymes of metabolic pathways involved in the utilization of dietary 337 fiber and the production of potentially beneficial metabolites (e.g. SCFAs). It is necessary 338 to identify and characterize these pathways in order to understand the components of the 339 microbiota and the microbiome that may underlie health effects associated with dietary 340 fiber intake. Members of the phyla Bacteroidetes and Firmicutes are specialized in the 341 utilization of complex carbohydrates and are the main producers of SCFAs. Butyrate and 342 propionate are the two most thoroughly investigated SCFAs in terms of their potential role 343 in metabolic health. The production of these SCFAs may require the participation of 344 different bacterial genera and species via cross-feeding mechanisms. For example, 345 Bacteroides thetaiotaomicron can directly produce propionate and acetate, which then can 346 be used by Eubacterium halli to produce butyrate (Mahowald, et al., 2009). Similar cross347 feeding mechanisms have been described between some Bifidobacterium spp. and 348 Faecalibacterium prausnitzii leading to increased butyrate production (Rios-Covian, 349 Gueimonde, Duncan, Flint, \& de los Reyes-Gavilan, 2015). Figure 1 shows the pathways 350 identified for bacterial production of butyrate by genomic and metagenomic analysis of the 351 human gut microbiota (Mahowald, et al., 2009; Reichardt, et al., 2014; Vital, Howe, \& 352 Tiedje, 2014). A conventional genetic signature to explore both the enrichment and 353 variability of butyrate producers is via analyzing the butyryl-CoA:acetate CoA-transferase 354 gene (BCoAT gene) encoding the respective enzyme responsible for the last step in butyrate 
355 production. Quantitative approaches indicate $B C o A T$ gene enrichment in gut microbiota 356 from individuals with a high intake of plant fiber, which is indicative of increased colonic 357 butyrate production (Hippe, et al., 2011; Louis, Young, Holtrop, \& Flint, 2010; Remely, et 358 al., 2014; Vital, Gao, Rizzo, Harrison, \& Tiedje, 2015).

359 Additionally to genes encoding enzymes of pathways responsible for SCFA production, the 360 detection of other genes involved in the uptake and degradation of complex polysaccharides 361 could be useful to define the active bacteria and their mode of action in response to fiber 362 intake. Pioneer studies regarding characterization of proteins involved in the utilization of 363 complex carbohydrates by anaerobe gut bacteria have revealed the essential role of 364 polypeptides encoded by Sus genes, extensively studied in B. thetaiotaomicron (Reeves, 365 Wang, \& Salyers, 1997). The Sus products were originally described as outer membrane 366 proteins able to bind complex starch. Notwithstanding, the genetic context of their encoding 367 genes has enabled the inclusion of glycoside hydrolases (GH) enzymes in the Sus repertoire 368 of proteins, which collectively work to produce small oligosaccharides that are more easily 369 imported by bacteria. Consequently, Sus genes have become useful to detect different 370 polysaccharide utilization loci (PULs) in other Bacteroides species by comparative 371 genomics approaches, allowing them to be studied in response to a wide variety of complex 372 polysaccharides (reviewed in (White, Lamed, Bayer, \& Flint, 2014)). Nowadays, research 373 on carbohydrate utilization by gut bacteria is conceived as a cornerstone to understand their 374 physiology and potential interactions and bidirectional communication with the host in 375 health and disease. In this regard, the Carbohydrate Active Enzymes (CAZy) database 376 (http://www.cazy.org/) is one of the most complete repositories describing the families of 377 structurally-related catalytic and carbohydrate-binding functional domains of enzymes that 378 bind, degrade, modify or create glycosidic bonds (Lombard, Golaconda Ramulu, Drula, 
379 Coutinho, \& Henrissat, 2013). Hierarchical classification of CAZy comprises 4 main 380 families such as the Glycoside Hydrolase (GH, with 135 subfamilies reported at Nov 2016), 381 the Glycosyltransferase (GT, with 101 subfamilies), the Polysaccharide Lyase (PL, with 24 382 subfamilies), and the Carbohydrate Esterase (CE, with 16 subfamilies) family. All GH 383 reported are classified according to the functional modules they contain, with the aim to 384 determine sites of action (exo or endo-acting enzymes) or type of cleavage ( $\alpha$ - or $\beta$ 385 glycosilases). Members of the phyla Bacteroidetes and Firmicutes are characterized by 386 encoding the largest set of $\mathrm{GH}$ in their genomes, thus exhibiting a remarkable versatility for 387 the utilization of different polysaccharides as carbon source (White et al 2014). These 388 features convert species of such bacterial phyla into key players for degradation of complex 389 polysaccharides in the human colon. Proof of this can be found in the studies performed in 390 Flint's lab with Ruminoccocus bromii in which this bacteria was observed to present a 391 specialized extracellular polypeptide complex, known as amylosome (Ze, et al., 2015). It 392 was also found to be an indispensable member of the human gut microbiota, having a direct 393 effect on energy recovery from a central component of diet, i.e., RS (Ze, Duncan, Louis, \& 394 Flint, 2012). However, Bifidobacterium (Actinobacteria) species are also well-known fiber 395 fermenters. Although Bifidobacteria have fewer GHs encoded in their genomes than 396 Bacteroidetes, they also exhibit a great versatility for the uptake and catabolism of 397 oligosaccharides. This versatility is well exemplified in genome-wide expression analyses, 398 which have disclosed a wide variety of genes appearing to respond specifically to different 399 carbon sources (Andersen, et al., 2013; O'Connell, et al., 2013). In this context, we have 400 recently described the genome response of B. pseudocatenulatum CECT 7765, a strain 401 isolated from breast-fed babies, during utilization of lactulose-derived oligosaccharides. An 
exhaustive inventory of GH enzymes present in the genome of this species have a set of

403 open reading frames (ORFs) that seem to control the uptake and degradation of this 404 digestion-resistant oligosaccharide (Benitez-Paez, Moreno, Sanz, \& Sanz, 2016).

405 Although GHs and related proteins appear to be the key traits to infer versatility of gut 406 microbes for utilization of polysaccharides and their contribution to the production of 407 fermentation end-products such as SCFAs, little is known about the effects of fiber 408 fermentation on secondary metabolic pathways and the generation of other nutrients (e.g. 409 amino acids and vitamins) and bioactive compounds. Some in vitro studies have reported 410 that oligosaccharide fermentation also increases amino acid synthesis (Benitez-Paez, et al., 411 2016; Sulek, et al., 2014). In particular, our study revealed that the utilization of GOS by $B$. 412 pseudocatenulatum CECT 7765, using bacteria cultures, increased the production and 413 extracellular accumulation of branched-chain amino acids such as leucine (Benitez-Paez, et 414 al., 2016). Additional studies are, however, needed to understand the effects of the interplay 415 between dietary fiber and amino acid metabolism in the large intestine and fully understand 416 the metabolites resulting from the activity of the gut microbiota and their potential consequences on health beyond the well-known SCFAs.

\section{Effects of dietary fiber on metabolic health mediated by gut microbiota}

420 There is a wealth of human intervention studies with dietary fibers, but only a few of them

421 have assessed the relationship between microbiota-induced changes and endpoints related 422 to physiological functions and metabolism. Further studies are also needed that directly 423 assess the effects of fiber-induced microbiota changes on metabolic outcomes, for example 424 via fecal transplantation or via inoculation of specific bacterial consortia from humans into 425 animal models. Consequently, there is still a large degree of uncertainty about to what 
extent the effects attributed to dietary fibers on metabolic health are mediated by gut microbiota in humans, and which are the key species involved. Nonetheless, considerable mechanistic data are available from other animal study approaches, as summarized below.

\subsection{Gut barrier integrity, metabolic endotoxemia and inflammation}

Obesity and particularly the intake of a high-fat diet (HFD) are thought to lead to a leaky gut and metabolic endotoxemia (increased serum LPS levels) in animal models and to some extent in humans. This is assumed contributing to the low-grade chronic inflammation leading to metabolic dysfunction and disease (metabolic syndrome and T2D). In fact, LPS is a potently inflammatory bacterial antigen linked to common metabolic diseases (Conlon \& Bird, 2015). LPS is an endotoxin consisting of three parts; lipid A, the oligosaccharide core and the O-antigen, with the lipid A causing endotoxicity. LPS is normally present in the human gut $(\geq 1 \mathrm{~g})$ and under normal conditions it does not cause negative health effects. In healthy humans the normal/low plasma concentration of LPS is 1-200 pg/ml, but increased levels have been found in subjects with obesity and diabetes (Erridge, Attina, Spickett, \& Webb, 2007; Moreira, Texeira, Ferreira, Peluzio Mdo, \& Alfenas Rde, 2012). LPS binds to TLR4 via CD14 on, for example, the membrane surface of immune cells leading to activation of genes that codify pro-inflammatory cytokines (e.g. TNF- $\alpha$ and IL6) involved in metabolic inflammation. Experimental models of obesity have shown prebiotic-induced increases in bifidobacteria and Akkermansia spp. associated with reduced endotoxemia and systemic inflammation (Cani, et al., 2007; Schneeberger, et al., 2015). These effects can be partly explained by the ability of those bacteria to ferment glycans leading to SCFA production and promoting local decrease of $\mathrm{pH}$, which may modulate gut microbiota composition and inhibit the growth of enterobacteria, which may be a source of 
LPS (Delzenne, Neyrinck, \& Cani, 2013; Everard, et al., 2013). This effect could also be 451 related to the role of SCFAs in strengthening the gut barrier function, which also reduces 452 LPS translocation via different mechanisms, including modulation of expression and 453 localization of tight-junction proteins, induction of endocrine peptide production (GLP-2) 454 and modification of the intestinal levels of endocannabinoids (Everard, et al., 2013).

455 SCFAs also play an anti-inflammatory role by regulating the size and function of the 456 colonic regulatory $\mathrm{T}$ cells (Treg), specifically inducing Foxp3+IL-10-producing Tregs 457 (Smith, et al., 2013). SCFAs may also interact with peroxisome proliferator-activated 458 receptor (PPAR) $\gamma$, thereby inhibiting pro-inflammatory signal transduction pathways (e.g. 459 nuclear factor-kappa B [NF-kB]) leading to reduction of downstream cytokine/chemokine 460 production (IL-6, IL-8, and MCP-1) in intestinal epithelial cells and metabolic tissues (e.g. 461 adipose tissue) (Mastrofrancesco, et al., 2014). Activation of PPAR $\gamma$ also seems to be 462 crucial in orchestrating Treg accumulation and function in the adipose tissue, which play an 463 important role in preventing inflammation and insulin resistance (Cipolletta, Cohen, 464 Spiegelman, Benoist, \& Mathis, 2015). Butyrate as well as other SCFAs, protects against 465 the liver inflammation process associated with steatosis by inhibiting the NF- $\mathrm{KB}$ activation 466 and downregulating expression of TLR4 receptor (Mattace Raso, et al., 2013). The 467 molecular mechanisms underlying SCFA modulation of NF- $\kappa$ B activity have recently been 468 disclosed as related to JNK and p38 kinases, which control NF- $\kappa$ B activity (Haghikia, et al., 469 2015). However, we cannot discard additional mechanisms to control NF- $\kappa$ B function 470 involving acetylation/deacetylation of histones and the RelA (p65) monomer itself (Davie, 471 2003; Glozak, Sengupta, Zhang, \& Seto, 2005). 


\subsection{Enteroendocrine secretion and appetite}

In obese animals fed inulin-type fructans, there is an increase in plasma anorexigenic peptides (peptide YY and glucagon-like peptide - GLP-1) and a decrease in the orexigenic peptide ghrelin, which increases satiety (reviewed in (Delzenne, et al., 2013)). In addition, supplementation with fructans in HFD-fed mice modulates neuronal activation within the arcuate nucleus, which can help to control food intake (Anastasovska, et al., 2012). These effects on anorexigenic peptide secretion could be mediated by interactions of SCFAs with G-protein receptors such as FFAR2 (GPR41) and FFAR3 (GPR43), which could explain induction of satiety and increased insulin sensitivity (Blaut, 2014). Also in humans, prebiotic interventions with fructans have led to increases in anorexigenic peptides and/or decreases in orexigenic (ghrelin) peptides (Cani, Joly, Horsmans, \& Delzenne, 2006; Cani, et al., 2009; Parnell \& Reimer, 2009; Verhoef, Meyer, \& Westerterp, 2011), but effects on satiety have not always been consistent (Peters, Boers, Haddeman, Melnikov, \& Qvyjt, 2009).

\subsection{Adiposity, lipid and glucose metabolism}

Reduced adiposity in rodents due to dietary supplementation with inulin-type fructans or AX has also been attributed to the role of SCFAs in modulating PPAR $\gamma$ expression via interaction with the G-protein coupled receptor protein FFAR3 (Delzenne, Neyrinck, Backhed, \& Cani, 2011). Interestingly, den Besten and co-workers found that SCFAs decrease PPAR $\gamma$ expression, thus promoting activity of the uncoupling protein 2 (UCP2) and, thereby, stimulating oxidative metabolism in liver and adipose tissue, insulin sensitivity and weight loss (den Besten, et al., 2015). Studies with inulin-type fructans have also shown they can decrease hepatic accumulation of triglycerides and/or cholesterol in 
497 liver tissue. These effects have been associated with a decrease in sterol-response-element-

498 binding protein-dependent cholesterogenesis, lipogenesis, or changes in PPAR $\alpha$-driven 499 fatty acid oxidation (reviewed in (Delzenne, et al., 2013)). The majority of studies show 500 prebiotic administration also leads to improved fasting or postprandial glycemia due to the 501 very low digestion rates of prebiotics compared with digestible carbohydrates (for review 502 see (Roberfroid, et al., 2010)). In addition, SCFA-stimulation of GLP-1 secretion can also 503 mediate an improvement in glucose metabolism, reducing obesity-related hepatic insulin 504 resistance.

505 In humans, intervention studies with fructans have reported modest effects on body weight 506 and fat mass in obese adults, but simultaneous changes in microbiota were not considered 507 to have any correlation (Genta, et al., 2009; Parnell \& Reimer, 2009). Nevertheless, there 508 are also reports of a lack of effect on body weight in obese children (Liber \& Szajewska, 509 2014). On the other hand, a rapid improvement in glucose tolerance has been observed for 510 individuals consuming WG barley the night prior to analysis. These results were thought to 511 be caused by the high amount of soluble dietary fiber and resistant starch contained in 512 barley kernels, which facilitated bacterial fermentation in the colon overnight and produced 513 significantly higher levels of SCFAs. This was indirectly measured from breath $\mathrm{H}_{2}$ 514 excretion (Nilsson, Granfeldt, Ostman, Preston, \& Bjorck, 2006). Moreover, recent results 515 of this dietary intervention model indicate that the fiber-associated improvement of glucose 516 metabolism is also associated with an increase in Prevotella spp. (Kovatcheva-Datchary, et 517 al., 2015).

\section{Impact of dietary fat on gut microbiota and associated metabolic endpoints}


520 Globally, an increase in dietary fat content is usually paralleled with a decrease in 521 carbohydrates, including dietary fiber content, thus making it difficult to attribute the 522 observed changes, at physiology or gut microbiota levels, exclusively to one of the 523 macronutrients whose proportion is being increased. Consequently, a decreased abundance 524 of butyrate-producing bacteria and lower fecal SCFA excretion following a HFD is most 525 likely caused by a decrease in dietary carbohydrate intake. Therefore, major conclusions 526 derived from future animal or human studies including HFD interventions must be 527 addressed carefully in order to consider confounding effects regarding the proportions and 528 energetics or other macronutrients administrated.

\subsection{Evidence from animal studies}

531 The role of gut microbiota in HFD-induced obesity was suggested through animal 532 experiments involving germ-free mice fed a HFD, which were protected from obesity 533 compared to conventionally raised mice (Rabot, et al., 2010), thus highlighting the role of 534 microbiota in HFD-induced obesity. Furthermore, a study in mice by Hildebrandt and coworkers showed that changes in the gut microbiota composition were caused by dietary fat content rather than the degree of obesity, suggesting that fat directly impacts on microbiota regardless of the metabolic phenotype (Hildebrandt, et al., 2009). Gut microbiota transferred to germ-free mice from conventionally raised mice resulted in weight gain and a higher relative abundance of Firmicutes and a lower abundance of

540 Bacteroidetes when mice were fed a HFD compared to a low-fat chow diet from 16 weeks 541 of age (Turnbaugh, Backhed, Fulton, \& Gordon, 2008). Although differences established at 542 phylum level are of limited value since each phylum comprise many different species 543 which may potentially play many different functions, a common trait for HFD-feding 
seems to be that it increases the Firmicutes:Bacteroidetes ratio (de Wit, et al., 2012;

545 Hildebrandt, et al., 2009; Lam, et al., 2012; Turnbaugh, et al., 2008), although there is not complete consistency across studies (Lecomte, et al., 2015); this would also be due to experimental and environmental differences. A recent 16-week study in mice fed a HFD reports that the abundance of Akkermansia muciniphila was progressively and drastically decreased while other groups including Bifidobacterium spp. and Lactobacillus spp. showed a transient decrease. In contrast the abundance of Roseburia spp. and Bilophila wadsworthia increased after 12 and 16 weeks upon HFD, respectively (Schneeberger, et al., 2015). Interesting, B.wadsworthia have been linked to insulin resistance and inflammation 553 in humans (Brahe, et al., 2015).

554 Animal studies have revealed different mechanisms by which HFDcould exert adverse 555 effects, partly mediated by the microbiota, on the host metabolic phenotype. For example, 556 diets rich in saturated fat may contribute to inflammation, a hallmark of metabolic 557 dysfunction leading to metabolic syndrome and T2D, by promoting the expansion of 558 pathobionts, reducing the proportion of protective bacteria, and promoting a leaky gut that 559 in turn facilitates the translocation of bacterial products (e.g. LPS) causing immune 560 activation (Caesar, et al., 2015; Delzenne, et al., 2011; Devkota, et al., 2012). In a recent 561 study, HFD-induced microbiota changes were correlated with obesity-related inflammatory 562 and metabolic biomarkers (Schneeberger, et al., 2015). Akkermansia muciniphila was the 563 species showing the clearest inverse associations with inflammatory markers in the adipose 564 tissue and also with biochemical/hormonal parameters in circulation (i.e., insulin, glucose, 565 triglycerides and leptin).

566 However, as the majority of the dietary fat is absorbed in the small intestine and does not 567 serve as an energy source for gut microbes, the effect of fat on gut microbiota must be 
partly mediated by indirect mechanisms. Increased fat intake also leads to increases in fat quantities and of BAs reaching the colon, and particularly the concentration and composition of BAs modulates the gut microbiota exerting antimicrobial effects (Islam, et al., 2011; Ridlon, Kang, Hylemon, \& Bajaj, 2014). Primary BAs (e.g. cholic acid [CA] and chenodeoxycholic acid [CDCA] in humans and beta-muricholic acid [ $\beta$-MCA] in mice) are sterol compounds synthesized from cholesterol in the liver, conjugated with taurine and glycine, and then secreted into the small intestine to emulsify lipids to facilitate their digestion and absorption. The majority of BAs are reabsorbed (enterohepatic recycling), but as increased fat intake leads to increased BA secretion, theoretically more BAs will escape enterohepatic recycling, and hence reach the large intestine. During the transit to the large intestine, primary BAs undergo deconjugation, oxidation of hydroxyl groups at C-3, C-7, andC-12, and $7 \alpha / \beta$-dehydroxylation reactions mediated by intestinal bacterial enzymes, yielding secondary BAs such as deoxycholic acid (DCA), lithocholic acid (LCA), and $\beta$ muri-deoxycholicacid. Bacterial bile salt hydrolases (BSH), e.g. produced by Clostridium spp, catalyze the first reaction on secondary BAs and this is a step necessary for the subsequent7 $\alpha / \beta$-dehydroxylation (Degirolamo, Rainaldi, Bovenga, Murzilli, \& Moschetta, 2014). Overall, the amount and composition of BAs are strongly influenced by gut microbiota and vice versa, and BA biotransformation has important biological consequences due to their role in dietary lipid absorption and as signaling molecules, modulating cholesterol and triglyceride metabolism and glucose and energy homeostasis (Degirolamo, et al., 2014; Staels \& Prawitt, 2013). Secondary BAs have strong antimicrobial activity (e.g. damage of the bacterial cell membrane by interaction with phospholipids) due to their amphipathic properties. For example, DCA has 10 times the bactericidal activity of CA (Islam, et al., 2011), therefore an increase in the proportion of 
secondary BAs following HFD very likely affects the microbiota composition. A rat study,

593 evaluating the effect of adding CA at different doses compared with controls (no CA 594 added), demonstrated adose-dependent increase of fecal BA and DCA (Islam, et al., 2011).

595 Furthermore, a dose-dependent decrease in fecal SCFA concentration was observed along 596 with a reduction in total bacterial count and an increase in Firmicutes at the expense of 597 primarily Bacteroidetes.

598 Dietary saturated fat compared to poly-unsaturated fatty acids (PUFAs) was also reported 599 to favor taurine conjugation of hepatic BAs, which caused an expansion of $\delta$ 600 Proteobacteria-type pathobionts, in particularly B. wadsworthia which is a sulfite-reducing 601 bacterium exerting a cytotoxic effect on epithelial cells and activating Th1-type 602 inflammatory response (Devkota, et al., 2012).

603 Studies in rodent models of HFD-induced obesity have also shown that saturated fat 604 reduces the mucus layer, which acts as the first barrier separating the immune system from 605 microbial and antigen interactions that may activate an inflammatory response. This effect 606 was parallel to a reduction in the abundance of Akkermansia spp., while administration of 607 this bacterium reversed it, increasing mucus layer thickness, and thus suggesting a 608 microbiota-mediated effect (Everard, et al., 2013). Other animal studies have reported 609 correlations between HFD-induced changes in the microbiota and alterations in the 610 expression of tight junction-related proteins, and in gut permeability. In mice a HFD has 611 been shown to reduce the expression of the tight-junction-related protein zonula occludens 612 (ZO)-1 mRNA (Cani, Delzenne, Amar, \& Burcelin, 2008) associated leading to increased 613 gut permeability measured by transepithelial resistance (Lam, et al., 2012). Additionally, 614 decreased transepithelial resistance (i.e. increased gut permeability) was associated a drop 
615 in the abundance of Lactobacillus spp. and augmented abundance of Oscillibacter spp. 616 (Lam, et al., 2012).

617 Animal studies also show that when a HFD is supplemented with either prebiotics (Cani, et 618 al., 2007; Everard, et al., 2013; Serino, et al., 2012) or antibiotics (Cani, Bibiloni, et al., 619 2008) the HFD-induced alterations in gut microbiota and metabolism are partially reversed, 620 indicating that gut microbiota partly mediate the consequences of HF feeding.

621 A few studies have investigated the effects of different dietary fatty acids (Lam, et al., 622 2012; Lappi, et al., 2013; Simoes, et al., 2013). In mice, it has been shown that n-6 high fat 623 diets do not increase insulin resistance, intestinal permeability and fat accumulation to the 624 same degree as saturated fatty acid diets, which is possibly due to a lower increase in $\mathrm{H}_{2} \mathrm{~S}$ 625 producing bacteria (Lam, et al., 2012). Likewise, lower decreases in Bacteroidetes have 626 been found under diets rich in n-3 or n-6, compared to diets rich in saturated fatty acids(T. 627 Liu, Hougen, Vollmer, \& Hiebert, 2012).

\subsection{Evidence from human studies}

630 Only a few human intervention studies have investigated the effects of HFD compared to 631 low-fat diets(LFD) or the type of fat (saturated fat versus PUFAs) in relation to changes in 632 gut microbiota and the metabolic consequences. As found in animal studies, total bacterial 633 counts decrease in humans who consume a HFD (35-38 E\%), compared to a LFD (23-27 634 E\%) over 24 weeks (Fava, et al., 2013). Moreover, low/moderate-fat intake appears to 635 induce a higher abundance of Bacteroides spp. and/or Bifidobacterium spp., compared to 636 high-fat intake in human intervention trials (Brinkworth, Noakes, Clifton, \& Bird, 2009; 637 Fava, et al., 2013). An energy-restricted HFD (58 E\%), compared with an isocaloric 638 moderate-fat diet (28 E \%) was shown to increase the total number of anaerobes in the 
moderate-fat group, but not in the high-fat group, but the ratio between anaerobe:aerobe

640 remained unchanged in each group (Brinkworth, et al., 2009). Additionally, a study

641 comparing high-fat and moderate-fat ad libitum diets (66 E\% vs. 35 E\%) over 4 weeks did

642 not report any effect on the gut microbiota in terms of total bacterial count; however, the

643 methodology used to study microbiota abundance was based on a limited number of

644 species(Duncan, et al., 2007).

645 As stated above, an increase in the intake of dietary fat is usually at expenses of a decrease 646 in that of simple or complex carbohydrates, making it difficult to attribute the observed 647 effectexclusively to one of the macronutrients. O'Keefe and coworkers (O'Keefe, et al., 648 2015) compared the effects on gut microbiota in a cross-over study with a 2-week diet 649 period administering either African- or American-food. The switch from a rural African to 650 an American-diet (52\% fat, 21\% carbohydrate, 27\% protein, and $12 \%$ fiber) decreased the 651 abundance of butyrate-producing bacteria and the production of acetate, propionate and 652 butyrate (O'Keefe, et al., 2015). Similarly, Duncan and coworkers observeda higher 653 abundance of Roseburia and Eubacterium and higher fecal excretion of butyrate in humans 654 following a moderate fat diet compared to high-fat intake, with these changes in the gut 655 microbiota and derived metabolites being positively correlated with carbohydrate intake 656 (Duncan, et al., 2007).

657 O'Keefe and coworkers also measured BA excretion and observed that the high-fat diet of 658 Americans was associated with increased expression of microbial genes coding for the 659 enzyme related to converting primary BAs to secondary BAs, whereas a dietary switch to a 660 lower-fat diet reduced the abundance of these bacteria. Furthermore, excretion of the 661 secondary BAs LCA and DCA was increased by the HFD. Also short-term consumption of 662 diets composed entirely of animal (rich in fat and protein) or plant products (rich in fiber) 
663 can rapidly alter gut microbial composition (David, et al., 2014). An animal-based diet 664 increased the abundance of bile-tolerant microorganisms, including Alistipes, Bilophila, and 665 Bacteroides species. By contrast this diet decreased the abundance of Firmicutes, including 666 genus and species specialized in the utilization of polysaccharides (Roseburia, Eubacterium 667 rectale, and Ruminococcus bromii). Furthermore, the animal-based diet increased the 668 abundance of B. wadsworthia and secondary BAs. These findings support the observations 669 in rodent models comparing diets rich in PUFA or saturated fat (D. L. Gibson, et al., 2015; 670 Schneeberger, et al., 2015), suggesting similar mechanisms of action and similar metabolic 671 effects.

672 The relationship between PUFAs and the microbiota are even less well understood. A 673 recent study in women with obesity and metabolic syndrome who consumed inulin-type 674 fructans for 3 months reported that PUFA-derived metabolites were associated with 675 Bifidobacterium spp., Eubacterium ventriosum, and Lactobacillus spp., and negatively 676 correlated with serum cholesterol (Druart, et al., 2014). However, another human 677 intervention study found that supplementation with n-3 fatty acids (180 mg EPA and 120 678 mg DHA) for 6 weeks did not induce changes in the gut microbiota although it decreased 679 insulin resistance and CRP (Rajkumar, et al., 2014). Unfortunately, amelioration of these 680 metabolic parameters could not be directly associated with one specific fatty acid since 681 only a mixture was tested. Therefore, further studies are needed to gain greater 682 understanding of how the quality of dietary fat influences gut microbiota composition and 683 function, and potential mediated effects on metabolism in humans.

684

\section{Concluding remarks}


686 Fiber is an instrumental dietary component that can be used to remodel gut microbiota 687 composition and function to potentiate the beneficial effects of healthy diets on body 688 weight management and metabolism. However, efforts are still needed to identify the 689 optimal functional partnership between key bacterial species and types of fibers, 690 considering the specificities of the individual's microbiota. Fermentation of dietary fiber 691 generates SCFAs, which presumably articulate beneficial effects in the context of obesity; 692 yet many other secondary metabolic products resulting from diet-microbe interactions have 693 yet to be discovered. Gut microbiota appears to contribute to the adverse consequences of 694 high-fat diets on the metabolic phenotype, aggravating the associated low-grade 695 inflammation and increasing energy absorption; however, further studies are needed to 696 understand the potential effects of the quality of dietary fat on the gut microbiota and 697 secondary metabolic process, such as those involving bile acids and their signaling roles. 698 Additional efforts must be conducted to identify the specific components of the gut 699 microbiota, at species and strain level, influenced by different types of dietary fibers and 700 fats and to understand their roles and mechanisms of action in humans to facilitate the use 701 of this information in nutritional practice. This ambitious goal is expected to be 702 accomplished by developing translational research approaches that integrate controlled 703 dietary interventions in humans, combining functional omics technologies and 704 physiological/clinical endpoints, and mechanistic studies in experimental models colonized 705 with specific dietary-driven human microbiotas. 
708 This works was supported by the European Union's Seventh Framework Program under the 709 grant agreement no 613979 (MyNewGut) and by FUNDACION MAPFRE under grant 710 "Hernando de Larramendi" call 2014.

711

712 


\section{References}

Abell, G. C., Cooke, C. M., Bennett, C. N., Conlon, M. A., \& McOrist, A. L. (2008). Phylotypes related to Ruminococcus bromii are abundant in the large bowel of humans and increase in response to a diet high in resistant starch. FEMS Microbiol Ecol, 66, 505-515.

Anastasovska, J., Arora, T., Sanchez Canon, G. J., Parkinson, J. R., Touhy, K., Gibson, G. R., Nadkarni, N. A., So, P. W., Goldstone, A. P., Thomas, E. L., Hankir, M. K., Van Loo, J., Modi, N., Bell, J. D., \& Frost, G. (2012). Fermentable carbohydrate alters hypothalamic neuronal activity and protects against the obesogenic environment. Obesity (Silver Spring), 20, 1016-1023.

Andersen, J. M., Barrangou, R., Abou Hachem, M., Lahtinen, S. J., Goh, Y. J., Svensson, B., \& Klaenhammer, T. R. (2013). Transcriptional analysis of oligosaccharide utilization by Bifidobacterium lactis B1-04. BMC Genomics, 14, 312.

Benitez-Paez, A., Moreno, F., Sanz, M., \& Sanz, Y. (2016). Genome structure of the symbiont Bifidobacterium pseudocatenulatum CECT 7765 and gene expression profiling in response to lactulosederived oligosaccharides. Front Microbiol, 7, 624.

Bes-Rastrollo, M., Martinez-Gonzalez, M. A., Sanchez-Villegas, A., de la Fuente Arrillaga, C., \& Martinez, J. A. (2006). Association of fiber intake and fruit/vegetable consumption with weight gain in a Mediterranean population. Nutrition, 22, 504-511.

Blaut, M. (2014). Gut microbiota and energy balance: role in obesity. Proc Nutr Soc, 74, 227-234.

Brahe, L. K., Le Chatelier, E., Prifti, E., Pons, N., Kennedy, S., Hansen, T., Pedersen, O., Astrup, A., Ehrlich, S. D., \& Larsen, L. H. (2015). Specific gut microbiota features and metabolic markers in postmenopausal women with obesity. Nutr Diabetes, 5, e159.

Brinkworth, G. D., Noakes, M., Clifton, P. M., \& Bird, A. R. (2009). Comparative effects of very lowcarbohydrate, high-fat and high-carbohydrate, low-fat weight-loss diets on bowel habit and faecal shortchain fatty acids and bacterial populations. Br J Nutr, 101, 1493-1502.

Broekaert, W. F., Courtin, C. M., Verbeke, K., Van de Wiele, T., Verstraete, W., \& Delcour, J. A. (2011). Prebiotic and other health-related effects of cereal-derived arabinoxylans, arabinoxylan-oligosaccharides, and xylooligosaccharides. Crit Rev Food Sci Nutr, 51, 178-194.

Caesar, R., Tremaroli, V., Kovatcheva-Datchary, P., Cani, P. D., \& Backhed, F. (2015). Crosstalk between Gut Microbiota and Dietary Lipids Aggravates WAT Inflammation through TLR Signaling. Cell Metab, 22, 658-668.

Cani, P. D., Bibiloni, R., Knauf, C., Waget, A., Neyrinck, A. M., Delzenne, N. M., \& Burcelin, R. (2008). Changes in gut microbiota control metabolic endotoxemia-induced inflammation in high-fat diet-induced obesity and diabetes in mice. Diabetes, 57, 1470-1481.

Cani, P. D., Delzenne, N. M., Amar, J., \& Burcelin, R. (2008). Role of gut microflora in the development of obesity and insulin resistance following high-fat diet feeding. Pathol Biol (Paris), 56, 305-309.

Cani, P. D., Joly, E., Horsmans, Y., \& Delzenne, N. M. (2006). Oligofructose promotes satiety in healthy human: a pilot study. Eur J Clin Nutr, 60, 567-572.

Cani, P. D., Lecourt, E., Dewulf, E. M., Sohet, F. M., Pachikian, B. D., Naslain, D., De Backer, F., Neyrinck, A. M., \& Delzenne, N. M. (2009). Gut microbiota fermentation of prebiotics increases satietogenic and incretin gut peptide production with consequences for appetite sensation and glucose response after a meal. Am J Clin Nutr, 90, 1236-1243.

Cani, P. D., Neyrinck, A. M., Fava, F., Knauf, C., Burcelin, R. G., Tuohy, K. M., Gibson, G. R., \& Delzenne, N. M. (2007). Selective increases of bifidobacteria in gut microflora improve high-fat-diet-induced diabetes in mice through a mechanism associated with endotoxaemia. Diabetologia, 50, 2374-2383.

Carvalho-Wells, A. L., Helmolz, K., Nodet, C., Molzer, C., Leonard, C., McKevith, B., Thielecke, F., Jackson, K. G., \& Tuohy, K. M. (2010). Determination of the in vivo prebiotic potential of a maize-based whole grain breakfast cereal: a human feeding study. Br J Nutr, 104, 1353-1356.

Cipolletta, D., Cohen, P., Spiegelman, B. M., Benoist, C., \& Mathis, D. (2015). Appearance and disappearance of the mRNA signature characteristic of Treg cells in visceral adipose tissue: age, diet, and PPARgamma effects. Proc Natl Acad Sci U S A, 112, $482-487$.

Cloetens, L., Broekaert, W. F., Delaedt, Y., Ollevier, F., Courtin, C. M., Delcour, J. A., Rutgeerts, P., \& Verbeke, K. (2010). Tolerance of arabinoxylan-oligosaccharides and their prebiotic activity in healthy subjects: a randomised, placebo-controlled cross-over study. Br J Nutr, 103, 703-713. 
Closa-Monasterolo, R., Gispert-Llaurado, M., Luque, V., Ferre, N., Rubio-Torrents, C., Zaragoza-Jordana, M., \& Escribano, J. (2013). Safety and efficacy of inulin and oligofructose supplementation in infant formula: results from a randomized clinical trial. Clin Nutr, 32, 918-927.

Conlon, M. A., \& Bird, A. R. (2015). The impact of diet and lifestyle on gut microbiota and human health. Nutrients, 1, 17-44.

Coppinger, T., Jeanes, Y. M., Dabinett, J., Vogele, C., \& Reeves, S. (2010). Physical activity and dietary intake of children aged 9-11 years and the influence of peers on these behaviours: a 1-year follow-up. Eur J Clin Nutr, 64, 776-781.

Costabile, A., Klinder, A., Fava, F., Napolitano, A., Fogliano, V., Leonard, C., Gibson, G. R., \& Tuohy, K. M. (2008). Whole-grain wheat breakfast cereal has a prebiotic effect on the human gut microbiota: a double-blind, placebo-controlled, crossover study. Br J Nutr, 99, 110-120.

Chassard, C., Goumy, V., Leclerc, M., Del'homme, C., \& Bernalier-Donadille, A. (2007). Characterization of the xylan-degrading microbial community from human faeces. FEMS Microbiol Ecol, 61, 121-131.

Chung, Y. C., Hsu, C. K., Ko, C. Y., \& Chan, Y. C. (2007). Dietary intake of xylooligosaccharides improves the intestinal microbiota, fecal moisture, an $\mathrm{pH}$ value in the elderly. Nutr Res, 27, 756-761.

David, L. A., Maurice, C. F., Carmody, R. N., Gootenberg, D. B., Button, J. E., Wolfe, B. E., Ling, A. V., Devlin, A. S., Varma, Y., Fischbach, M. A., Biddinger, S. B., Dutton, R. J., \& Turnbaugh, P. J. (2014). Diet rapidly and reproducibly alters the human gut microbiome. Nature, 505, 559-563.

Davie, J. R. (2003). Inhibition of histone deacetylase activity by butyrate. J Nutr, 133, 2485S-2493S.

De Filippis, F., Pellegrini, N., Vannini, L., Jeffery, I. B., La Storia, A., Laghi, L., Serrazanetti, D. I., Di Cagno, R., Ferrocino, I., Lazzi, C., Turroni, S., Cocolin, L., Brigidi, P., Neviani, E., Gobbetti, M., O'Toole, P. W., \& Ercolini, D. (2015). High-level adherence to a Mediterranean diet beneficially impacts the gut microbiota and associated metabolome. Gut, doi: 10.1136/gutjnl-2015-309957.

De Filippo, C., Cavalieri, D., Di Paola, M., Ramazzotti, M., Poullet, J. B., Massart, S., Collini, S., Pieraccini, G., \& Lionetti, P. (2010). Impact of diet in shaping gut microbiota revealed by a comparative study in children from Europe and rural Africa. Proc Natl Acad Sci U S A, 107, 14691-14696.

de Wit, N., Derrien, M., Bosch-Vermeulen, H., Oosterink, E., Keshtkar, S., Duval, C., de Vogel-van den Bosch, J., Kleerebezem, M., Muller, M., \& van der Meer, R. (2012). Saturated fat stimulates obesity and hepatic steatosis and affects gut microbiota composition by an enhanced overflow of dietary fat to the distal intestine. Am J Physiol Gastrointest Liver Physiol, 303, G589-599.

Degirolamo, C., Rainaldi, S., Bovenga, F., Murzilli, S., \& Moschetta, A. (2014). Microbiota modification with probiotics induces hepatic bile acid synthesis via downregulation of the Fxr-Fgf15 axis in mice. Cell Rep, 7, 12-18.

Delzenne, N. M., Neyrinck, A. M., Backhed, F., \& Cani, P. D. (2011). Targeting gut microbiota in obesity: effects of prebiotics and probiotics. Nat Rev Endocrinol, 7, 639-646.

Delzenne, N. M., Neyrinck, A. M., \& Cani, P. D. (2013). Gut microbiota and metabolic disorders: How prebiotic can work? Br J Nutr, 109 Suppl 2, S81-85.

den Besten, G., Bleeker, A., Gerding, A., van Eunen, K., Havinga, R., van Dijk, T. H., Oosterveer, M. H., Jonker, J. W., Groen, A. K., Reijngoud, D. J., \& Bakker, B. M. (2015). Short-Chain Fatty Acids protect against High-Fat Diet-Induced Obesity via a PPARgamma-dependent switch from lipogenesis to fat oxidation. Diabetes, 65, 2398-2408.

Devkota, S., Wang, Y., Musch, M. W., Leone, V., Fehlner-Peach, H., Nadimpalli, A., Antonopoulos, D. A., Jabri, B., \& Chang, E. B. (2012). Dietary-fat-induced taurocholic acid promotes pathobiont expansion and colitis in I110-/- mice. Nature, 487, 104-108.

Dewulf, E. M., Cani, P. D., Claus, S. P., Fuentes, S., Puylaert, P. G., Neyrinck, A. M., Bindels, L. B., de Vos, W. M., Gibson, G. R., Thissen, J. P., \& Delzenne, N. M. (2013). Insight into the prebiotic concept: lessons from an exploratory, double blind intervention study with inulin-type fructans in obese women. Gut, 62, 1112-1121.

Druart, C., Dewulf, E. M., Cani, P. D., Neyrinck, A. M., Thissen, J. P., \& Delzenne, N. M. (2014). Gut microbial metabolites of polyunsaturated fatty acids correlate with specific fecal bacteria and serum markers of metabolic syndrome in obese women. Lipids, 49, 397-402.

Duncan, S. H., Belenguer, A., Holtrop, G., Johnstone, A. M., Flint, H. J., \& Lobley, G. E. (2007). Reduced dietary intake of carbohydrates by obese subjects results in decreased concentrations of butyrate and butyrate-producing bacteria in feces. Appl Environ Microbiol, 73, 1073-1078. 
EFSA. (2014). Scientific opinion on the substantation of a health claim related to non-digestible carbohydrates and a reduction of post-pandrial glycaemic responses pursuant to Article 13(5) of Regulation (EC) No 1924/2006. EFSA J, 12, 3513.

EFSA NDA Panel. (2010). Scientific opinion on dietary reference values for carbohydrates and dietary fiber. EFSA $J, 8,1462$.

Erridge, C., Attina, T., Spickett, C. M., \& Webb, D. J. (2007). A high-fat meal induces low-grade endotoxemia: evidence of a novel mechanism of postprandial inflammation. Am J Clin Nutr, 86, 12861292.

Everard, A., Belzer, C., Geurts, L., Ouwerkerk, J. P., Druart, C., Bindels, L. B., Guiot, Y., Derrien, M., Muccioli, G. G., Delzenne, N. M., de Vos, W. M., \& Cani, P. D. (2013). Cross-talk between Akkermansia muciniphila and intestinal epithelium controls diet-induced obesity. Proc Natl Acad Sci U S A, 110, 90669071.

Fava, F., Gitau, R., Griffin, B. A., Gibson, G. R., Tuohy, K. M., \& Lovegrove, J. A. (2013). The type and quantity of dietary fat and carbohydrate alter faecal microbiome and short-chain fatty acid excretion in a metabolic syndrome 'at-risk' population. Int J Obes (Lond), 37, 216-223.

Flint, H. J., Duncan, S. H., Scott, K. P., \& Louis, P. (2015). Links between diet, gut microbiota composition and gut metabolism. Proc Nutr Soc, 74, 13-22.

Francois, I. E., Lescroart, O., Veraverbeke, W. S., Marzorati, M., Possemiers, S., Evenepoel, P., Hamer, H., Houben, E., Windey, K., Welling, G. W., Delcour, J. A., Courtin, C. M., Verbeke, K., \& Broekaert, W. F. (2012). Effects of a wheat bran extract containing arabinoxylan oligosaccharides on gastrointestinal health parameters in healthy adult human volunteers: a double-blind, randomised, placebo-controlled, cross-over trial. Br J Nutr, 108, 2229-2242.

Garcia-Peris, P., Velasco, C., Lozano, M. A., Moreno, Y., Paron, L., de la Cuerda, C., Breton, I., Camblor, M., Garcia-Hernandez, J., Guarner, F., \& Hernandez, M. (2012). Effect of a mixture of inulin and fructooligosaccharide on Lactobacillus and Bifidobacterium intestinal microbiota of patients receiving radiotherapy: a randomised, double-blind, placebo-controlled trial. Nutr Hosp, 27, 1908-1915.

Genta, S., Cabrera, W., Habib, N., Pons, J., Carillo, I. M., Grau, A., \& Sanchez, S. (2009). Yacon syrup: beneficial effects on obesity and insulin resistance in humans. Clin Nutr, 28, 182-187.

Gibson, D. L., Gill, S. K., Brown, K., Tasnim, N., Ghosh, S., Innis, S., \& Jacobson, K. (2015). Maternal exposure to fish oil primes offspring to harbor intestinal pathobionts associated with altered immune cell balance. Gut Microbes, 6, 24-32.

Gibson, G. R. (2004). Fibre and effects on probiotics (the prebiotic concept). Clin Nutr Suppl, 1, 25-31.

Gibson, G. R., Probert, H. M., Loo, J. V., Rastall, R. A., \& Roberfroid, M. B. (2004). Dietary modulation of the human colonic microbiota: updating the concept of prebiotics. Nutr Res Rev, 17, 259-275.

Giovannini, M., Verduci, E., Gregori, D., Ballali, S., Soldi, S., Ghisleni, D., \& Riva, E. (2014). Prebiotic effect of an infant formula supplemented with galacto-oligosaccharides: randomized multicenter trial. $J$ Am Coll Nutr, 33, 385-393.

Glozak, M. A., Sengupta, N., Zhang, X., \& Seto, E. (2005). Acetylation and deacetylation of non-histone proteins. Gene, 363, 15-23.

Gregor, M. F., \& Hotamisligil, G. S. (2011). Inflammatory mechanisms in obesity. Annu Rev Immunol, 29, 415-445.

Haghikia, A., Jorg, S., Duscha, A., Berg, J., Manzel, A., Waschbisch, A., Hammer, A., Lee, D. H., May, C., Wilck, N., Balogh, A., Ostermann, A. I., Schebb, N. H., Akkad, D. A., Grohme, D. A., Kleinewietfeld, M., Kempa, S., Thone, J., Demir, S., Muller, D. N., Gold, R., \& Linker, R. A. (2015). Dietary Fatty Acids Directly Impact Central Nervous System Autoimmunity via the Small Intestine. Immunity, 43, 817-829.

Hascoet, J. M., Hubert, C., Rochat, F., Legagneur, H., Gaga, S., Emady-Azar, S., \& Steenhout, P. G. (2011). Effect of formula composition on the development of infant gut microbiota. J Pediatr Gastroenterol Nutr, 52, 756-762.

Hildebrandt, M. A., Hoffmann, C., Sherrill-Mix, S. A., Keilbaugh, S. A., Hamady, M., Chen, Y. Y., Knight, R., Ahima, R. S., Bushman, F., \& Wu, G. D. (2009). High-fat diet determines the composition of the murine gut microbiome independently of obesity. Gastroenterology, 137, 1716-1724 e1711-1712.

Hippe, B., Zwielehner, J., Liszt, K., Lassl, C., Unger, F., \& Haslberger, A. G. (2011). Quantification of butyryl CoA:acetate CoA-transferase genes reveals different butyrate production capacity in individuals according to diet and age. FEMS Microbiol Lett, 316, 130-135. 
Holscher, H. D., Bauer, L. L., Gourineni, V., Pelkman, C. L., Fahey, G. C., Jr., \& Swanson, K. S. (2015). Agave Inulin Supplementation Affects the Fecal Microbiota of Healthy Adults Participating in a Randomized, Double-Blind, Placebo-Controlled, Crossover Trial. J Nutr, 145, 2025-2032.

Hutkins, R. W., Krumbeck, J. A., Bindels, L. B., Cani, P. D., Fahey, G., Jr., Goh, Y. J., Hamaker, B., Martens, E. C., Mills, D. A., Rastal, R. A., Vaughan, E., \& Sanders, M. E. (2016). Prebiotics: why definitions matter. Curr Opin Biotechnol, 37, 1-7.

Islam, K. B., Fukiya, S., Hagio, M., Fujii, N., Ishizuka, S., Ooka, T., Ogura, Y., Hayashi, T., \& Yokota, A. (2011). Bile acid is a host factor that regulates the composition of the cecal microbiota in rats. Gastroenterology, 141, 1773-1781.

Jia, G., DeMarco, V. G., \& Sowers, J. R. (2016). Insulin resistance and hyperinsulinaemia in diabetic cardiomyopathy. Nat Rev Endocrinol, 12, 144-153.

Johnson, A. M., \& Olefsky, J. M. (2013). The origins and drivers of insulin resistance. Cell, 152, 673-684.

Koh-Banerjee, P., \& Rimm, E. B. (2003). Whole grain consumption and weight gain: a review of the epidemiological evidence, potential mechanisms and opportunities for future research. Proc Nutr Soc, 62, 25-29.

Korpela, K., Flint, H. J., Johnstone, A. M., Lappi, J., Poutanen, K., Dewulf, E., Delzenne, N., de Vos, W. M., \& Salonen, A. (2014). Gut microbiota signatures predict host and microbiota responses to dietary interventions in obese individuals. PLoS One, 9, e90702.

Kovatcheva-Datchary, P., Nilsson, A., Akrami, R., Lee, Y. S., De Vadder, F., Arora, T., Hallen, A., Martens, E., Bjorck, I., \& Backhed, F. (2015). Dietary Fiber-Induced Improvement in Glucose Metabolism Is Associated with Increased Abundance of Prevotella. Cell Metab, 22, 971-982.

Lam, Y. Y., Ha, C. W., Campbell, C. R., Mitchell, A. J., Dinudom, A., Oscarsson, J., Cook, D. I., Hunt, N. H., Caterson, I. D., Holmes, A. J., \& Storlien, L. H. (2012). Increased gut permeability and microbiota change associate with mesenteric fat inflammation and metabolic dysfunction in diet-induced obese mice. PLoS One, 7, e34233.

Lappi, J., Salojarvi, J., Kolehmainen, M., Mykkanen, H., Poutanen, K., de Vos, W. M., \& Salonen, A. (2013). Intake of whole-grain and fiber-rich rye bread versus refined wheat bread does not differentiate intestinal microbiota composition in Finnish adults with metabolic syndrome. J Nutr, 143, 648-655.

Lecomte, V., Kaakoush, N. O., Maloney, C. A., Raipuria, M., Huinao, K. D., Mitchell, H. M., \& Morris, M. J. (2015). Changes in gut microbiota in rats fed a high fat diet correlate with obesity-associated metabolic parameters. PLoS One, 10, e0126931.

Liber, A., \& Szajewska, H. (2014). Effect of oligofructose supplementation on body weight in overweight and obese children: a randomised, double-blind, placebo-controlled trial. Br J Nutr, 112, 2068-2074.

Liu, S., Manson, J. E., Stampfer, M. J., Rexrode, K. M., Hu, F. B., Rimm, E. B., \& Willett, W. C. (2000). Whole grain consumption and risk of ischemic stroke in women: A prospective study. Jama, 284, 15341540.

Liu, T., Hougen, H., Vollmer, A. C., \& Hiebert, S. M. (2012). Gut bacteria profiles of Mus musculus at the phylum and family levels are influenced by saturation of dietary fatty acids. Anaerobe, 18, 331-337.

Lombard, V., Golaconda Ramulu, H., Drula, E., Coutinho, P. M., \& Henrissat, B. (2013). The carbohydrateactive enzymes database (CAZy) in 2013. Nucleic Acids Res, 42, D490-495.

Louis, P., Young, P., Holtrop, G., \& Flint, H. J. (2010). Diversity of human colonic butyrate-producing bacteria revealed by analysis of the butyryl-CoA:acetate CoA-transferase gene. Environ Microbiol, 12, 304-314.

Ludwig, D. S., Pereira, M. A., Kroenke, C. H., Hilner, J. E., Van Horn, L., Slattery, M. L., \& Jacobs, D. R., Jr. (1999). Dietary fiber, weight gain, and cardiovascular disease risk factors in young adults. Jama, 282, $1539-1546$.

Ma, Z., \& Boye, J. I. (2016). Research Advances on Structural Characterization of Resistant Starch and Its Structure-Physiological Function Relationship: A Review. Crit Rev Food Sci Nutr, 56, doi: 10.1080/10408398.10402016.11230537.

Mahowald, M. A., Rey, F. E., Seedorf, H., Turnbaugh, P. J., Fulton, R. S., Wollam, A., Shah, N., Wang, C., Magrini, V., Wilson, R. K., Cantarel, B. L., Coutinho, P. M., Henrissat, B., Crock, L. W., Russell, A., Verberkmoes, N. C., Hettich, R. L., \& Gordon, J. I. (2009). Characterizing a model human gut microbiota composed of members of its two dominant bacterial phyla. Proc Natl Acad Sci U S A, 106, 5859-5864.

Maki, K. C., Gibson, G. R., Dickmann, R. S., Kendall, C. W., Chen, C. Y., Costabile, A., Comelli, E. M., McKay, D. L., Almeida, N. G., Jenkins, D., Zello, G. A., \& Blumberg, J. B. (2012). Digestive and 
physiologic effects of a wheat bran extract, arabino-xylan-oligosaccharide, in breakfast cereal. Nutrition, 28, 1115-1121.

Martinez, I., Kim, J., Duffy, P. R., Schlegel, V. L., \& Walter, J. (2010). Resistant starches types 2 and 4 have differential effects on the composition of the fecal microbiota in human subjects. PLoS One, 5, e15046.

Martinez, I., Lattimer, J. M., Hubach, K. L., Case, J. A., Yang, J., Weber, C. G., Louk, J. A., Rose, D. J., Kyureghian, G., Peterson, D. A., Haub, M. D., \& Walter, J. (2013). Gut microbiome composition is linked to whole grain-induced immunological improvements. ISME J, 7, 269-280.

Mastrofrancesco, A., Kovacs, D., Sarra, M., Bastonini, E., Cardinali, G., Aspite, N., Camera, E., Chavatte, P., Desreumaux, P., Monteleone, G., \& Picardo, M. (2014). Preclinical studies of a specific PPARgamma modulator in the control of skin inflammation. J Invest Dermatol, 134, 1001-1011.

Mattace Raso, G., Simeoli, R., Russo, R., Iacono, A., Santoro, A., Paciello, O., Ferrante, M. C., Canani, R. B., Calignano, A., \& Meli, R. (2013). Effects of sodium butyrate and its synthetic amide derivative on liver inflammation and glucose tolerance in an animal model of steatosis induced by high fat diet. PLoS One, 8, e68626.

McCleary, B. V. (2003). Dietary fibre analysis. Proc Nutr Soc, 62, 3-9.

Menezes, E. W., Grande, F., Giuntini, E. B., Lopes Tdo, V., Dan, M. C., Prado, S. B., Franco, B. D., Charrondiere, U. R., \& Lajolo, F. M. (2016). Impact of dietary fiber energy on the calculation of food total energy value in the Brazilian Food Composition Database. Food Chem, 193, 128-133.

Moens, F., Weckx, S., \& De Vuyst, L. (2016). Bifidobacterial inulin-type fructan degradation capacity determines cross-feeding interactions between bifidobacteria and Faecalibacterium prausnitzii. Int $J$ Food Microbiol, 231, 76-85.

Moreira, A. P., Texeira, T. F., Ferreira, A. B., Peluzio Mdo, C., \& Alfenas Rde, C. (2012). Influence of a high-fat diet on gut microbiota, intestinal permeability and metabolic endotoxaemia. Br J Nutr, 108, 801809.

Moya-Perez, A., Neef, A., \& Sanz, Y. (2015). Bifidobacterium pseudocatenulatum CECT 7765 Reduces Obesity-Associated Inflammation by Restoring the Lymphocyte-Macrophage Balance and Gut Microbiota Structure in High-Fat Diet-Fed Mice. PLoS One, 10, e0126976.

Nichenametla, S. N., Weidauer, L. A., Wey, H. E., Beare, T. M., Specker, B. L., \& Dey, M. (2014). Resistant starch type 4-enriched diet lowered blood cholesterols and improved body composition in a double blind controlled cross-over intervention. Mol Nutr Food Res, 58, 1365-1369.

Nilsson, A., Granfeldt, Y., Ostman, E., Preston, T., \& Bjorck, I. (2006). Effects of GI and content of indigestible carbohydrates of cereal-based evening meals on glucose tolerance at a subsequent standardised breakfast. Eur J Clin Nutr, 60, 1092-1099.

O'Connell, K. J., O'Connell Motherway, M., O'Callaghan, J., Fitzgerald, G. F., Ross, R. P., Ventura, M., Stanton, C., \& van Sinderen, D. (2013). Metabolism of four alpha-glycosidic linkage-containing oligosaccharides by Bifidobacterium breve UCC2003. Appl Environ Microbiol, 79, 6280-6292.

O'Keefe, S. J., Li, J. V., Lahti, L., Ou, J., Carbonero, F., Mohammed, K., Posma, J. M., Kinross, J., Wahl, E., Ruder, E., Vipperla, K., Naidoo, V., Mtshali, L., Tims, S., Puylaert, P. G., DeLany, J., Krasinskas, A., Benefiel, A. C., Kaseb, H. O., Newton, K., Nicholson, J. K., de Vos, W. M., Gaskins, H. R., \& Zoetendal, E. G. (2015). Fat, fibre and cancer risk in African Americans and rural Africans. Nat Commun, 6, 6342.

Ou, J., Carbonero, F., Zoetendal, E. G., DeLany, J. P., Wang, M., Newton, K., Gaskins, H. R., \& O'Keefe, S. J. (2013). Diet, microbiota, and microbial metabolites in colon cancer risk in rural Africans and African Americans. Am J Clin Nutr, 98, 111-120.

Parnell, J. A., \& Reimer, R. A. (2009). Weight loss during oligofructose supplementation is associated with decreased ghrelin and increased peptide YY in overweight and obese adults. Am J Clin Nutr, 89, 17511759.

Peters, H. P., Boers, H. M., Haddeman, E., Melnikov, S. M., \& Qvyjt, F. (2009). No effect of added betaglucan or of fructooligosaccharide on appetite or energy intake. Am J Clin Nutr, 89, 58-63.

Petry, N., Egli, I., Chassard, C., Lacroix, C., \& Hurrell, R. (2012). Inulin modifies the bifidobacteria population, fecal lactate concentration, and fecal $\mathrm{pH}$ but does not influence iron absorption in women with low iron status. Am J Clin Nutr, 96, 325-331.

Rabot, S., Membrez, M., Bruneau, A., Gerard, P., Harach, T., Moser, M., Raymond, F., Mansourian, R., \& Chou, C. J. (2010). Germ-free C57BL/6J mice are resistant to high-fat-diet-induced insulin resistance and have altered cholesterol metabolism. Faseb J, 24, 4948-4959. 
Rajkumar, H., Mahmood, N., Kumar, M., Varikuti, S. R., Challa, H. R., \& Myakala, S. P. (2014). Effect of probiotic (VSL\#3) and omega-3 on lipid profile, insulin sensitivity, inflammatory markers, and gut colonization in overweight adults: a randomized, controlled trial. Mediators Inflamm, 2014, 348959.

Reeves, A. R., Wang, G. R., \& Salyers, A. A. (1997). Characterization of four outer membrane proteins that play a role in utilization of starch by Bacteroides thetaiotaomicron. J Bacteriol, 179, 643-649.

Reichardt, N., Duncan, S. H., Young, P., Belenguer, A., McWilliam Leitch, C., Scott, K. P., Flint, H. J., \& Louis, P. (2014). Phylogenetic distribution of three pathways for propionate production within the human gut microbiota. ISME J, 8, 1323-1335.

Remely, M., Aumueller, E., Merold, C., Dworzak, S., Hippe, B., Zanner, J., Pointner, A., Brath, H., \& Haslberger, A. G. (2014). Effects of short chain fatty acid producing bacteria on epigenetic regulation of FFAR3 in type 2 diabetes and obesity. Gene, 537, 85-92.

Ridlon, J. M., Kang, D. J., Hylemon, P. B., \& Bajaj, J. S. (2014). Bile acids and the gut microbiome. Curr Opin Gastroenterol, 30, 332-338.

Rios-Covian, D., Gueimonde, M., Duncan, S. H., Flint, H. J., \& de los Reyes-Gavilan, C. G. (2015). Enhanced butyrate formation by cross-feeding between Faecalibacterium prausnitzii and Bifidobacterium adolescentis. FEMS Microbiol Lett, 362.

Riviere, A., Selak, M., Lantin, D., Leroy, F., \& De Vuyst, L. (2016). Bifidobacteria and Butyrate-Producing Colon Bacteria: Importance and Strategies for Their Stimulation in the Human Gut. Front Microbiol, 7, 979.

Roberfroid, M., Gibson, G. R., Hoyles, L., McCartney, A. L., Rastall, R., Rowland, I., Wolvers, D., Watzl, B., Szajewska, H., Stahl, B., Guarner, F., Respondek, F., Whelan, K., Coxam, V., Davicco, M. J., Leotoing, L., Wittrant, Y., Delzenne, N. M., Cani, P. D., Neyrinck, A. M., \& Meheust, A. (2010). Prebiotic effects: metabolic and health benefits. Br J Nutr, 104 Suppl 2, S1-63.

Salazar, N., Dewulf, E. M., Neyrinck, A. M., Bindels, L. B., Cani, P. D., Mahillon, J., de Vos, W. M., Thissen, J. P., Gueimonde, M., de Los Reyes-Gavilan, C. G., \& Delzenne, N. M. (2015). Inulin-type fructans modulate intestinal Bifidobacterium species populations and decrease fecal short-chain fatty acids in obese women. Clin Nutr, 34, 501-507.

Sanz, Y., Olivares, M., Moya-Perez, A., \& Agostoni, C. (2015). Understanding the role of gut microbiome in metabolic disease risk. Pediatr Res, 77, 236-244.

Sanz, Y., Rastmanesh, R., \& Agostoni, C. (2013). Understanding the role of gut microbes and probiotics in obesity: how far are we? Pharmacol Res, 69, 144-155.

Scott, K. P., Gratz, S. W., Sheridan, P. O., Flint, H. J., \& Duncan, S. H. (2013). The influence of diet on the gut microbiota. Pharmacol Res, 69, 52-60.

Schneeberger, M., Everard, A., Gomez-Valades, A. G., Matamoros, S., Ramirez, S., Delzenne, N. M., Gomis, R., Claret, M., \& Cani, P. D. (2015). Akkermansia muciniphila inversely correlates with the onset of inflammation, altered adipose tissue metabolism and metabolic disorders during obesity in mice. Sci Rep, $5,16643$.

Schwiertz, A., Taras, D., Schafer, K., Beijer, S., Bos, N. A., Donus, C., \& Hardt, P. D. (2010). Microbiota and SCFA in lean and overweight healthy subjects. Obesity (Silver Spring), 18, 190-195.

Semova, I., Carten, J. D., Stombaugh, J., Mackey, L. C., Knight, R., Farber, S. A., \& Rawls, J. F. (2012). Microbiota regulate intestinal absorption and metabolism of fatty acids in the zebrafish. Cell Host Microbe, 12, 277-288.

Serino, M., Luche, E., Gres, S., Baylac, A., Berge, M., Cenac, C., Waget, A., Klopp, P., Iacovoni, J., Klopp, C., Mariette, J., Bouchez, O., Lluch, J., Ouarne, F., Monsan, P., Valet, P., Roques, C., Amar, J., Bouloumie, A., Theodorou, V., \& Burcelin, R. (2012). Metabolic adaptation to a high-fat diet is associated with a change in the gut microbiota. Gut, 61, 543-553.

Simoes, C. D., Maukonen, J., Kaprio, J., Rissanen, A., Pietilainen, K. H., \& Saarela, M. (2013). Habitual dietary intake is associated with stool microbiota composition in monozygotic twins. J Nutr, 143, 417-423.

Smith, P. M., Howitt, M. R., Panikov, N., Michaud, M., Gallini, C. A., Bohlooly, Y. M., Glickman, J. N., \& Garrett, W. S. (2013). The microbial metabolites, short-chain fatty acids, regulate colonic Treg cell homeostasis. Science, 341, 569-573.

Sonnenburg, E. D., Smits, S. A., Tikhonov, M., Higginbottom, S. K., Wingreen, N. S., \& Sonnenburg, J. L. (2016). Diet-induced extinctions in the gut microbiota compound over generations. Nature, 529, 212-215.

Staels, B., \& Prawitt, J. (2013). Soaping up type 2 diabetes with bile acids?: the link between glucose and bile acid metabolism in humans tightens: quality matters! Diabetes, 62, 3987-3989. 
Sulek, K., Vigsnaes, L. K., Schmidt, L. R., Holck, J., Frandsen, H. L., Smedsgaard, J., Skov, T. H., Meyer, A. S., \& Licht, T. R. (2014). A combined metabolomic and phylogenetic study reveals putatively prebiotic effects of high molecular weight arabino-oligosaccharides when assessed by in vitro fermentation in bacterial communities derived from humans. Anaerobe, 28, 68-77.

Turnbaugh, P. J., Backhed, F., Fulton, L., \& Gordon, J. I. (2008). Diet-induced obesity is linked to marked but reversible alterations in the mouse distal gut microbiome. Cell Host Microbe, 3, 213-223.

Turnbaugh, P. J., Ley, R. E., Mahowald, M. A., Magrini, V., Mardis, E. R., \& Gordon, J. I. (2006). An obesity-associated gut microbiome with increased capacity for energy harvest. Nature, 444, 1027-1031.

Ussar, S., Griffin, N. W., Bezy, O., Fujisaka, S., Vienberg, S., Softic, S., Deng, L., Bry, L., Gordon, J. I., \& Kahn, C. R. (2015). Interactions between Gut Microbiota, Host Genetics and Diet Modulate the Predisposition to Obesity and Metabolic Syndrome. Cell Metab, 22, 516-530.

Verhoef, S. P., Meyer, D., \& Westerterp, K. R. (2011). Effects of oligofructose on appetite profile, glucagonlike peptide 1 and peptide YY3-36 concentrations and energy intake. Br J Nutr, 106, 1757-1762.

Vital, M., Gao, J., Rizzo, M., Harrison, T., \& Tiedje, J. M. (2015). Diet is a major factor governing the fecal butyrate-producing community structure across Mammalia, Aves and Reptilia. ISME J, 9, 832-843.

Vital, M., Howe, A. C., \& Tiedje, J. M. (2014). Revealing the bacterial butyrate synthesis pathways by analyzing (meta)genomic data. MBio, 5, e00889.

Vrieze, A., Holleman, F., Zoetendal, E. G., de Vos, W. M., Hoekstra, J. B., \& Nieuwdorp, M. (2010). The environment within: how gut microbiota may influence metabolism and body composition. Diabetologia, 53, 606-613.

Vulevic, J., Juric, A., Tzortzis, G., \& Gibson, G. R. (2013). A mixture of trans-galactooligosaccharides reduces markers of metabolic syndrome and modulates the fecal microbiota and immune function of overweight adults. $J$ Nutr, 143, 324-331.

Walker, A. W., Ince, J., Duncan, S. H., Webster, L. M., Holtrop, G., Ze, X., Brown, D., Stares, M. D., Scott, P., Bergerat, A., Louis, P., McIntosh, F., Johnstone, A. M., Lobley, G. E., Parkhill, J., \& Flint, H. J. (2011). Dominant and diet-responsive groups of bacteria within the human colonic microbiota. ISME J, 5, 220-230.

World Health Organization. (2015). Fact Sheets. In Fact Sheet $N^{o} 311$.

Wu, X., Ma, C., Han, L., Nawaz, M., Gao, F., Zhang, X., Yu, P., Zhao, C., Li, L., Zhou, A., Wang, J., Moore, J. E., Millar, B. C., \& Xu, J. (2010). Molecular characterisation of the faecal microbiota in patients with type II diabetes. Curr Microbiol, 61, 69-78.

Xiao, S., Fei, N., Pang, X., Shen, J., Wang, L., Zhang, B., Zhang, M., Zhang, X., Zhang, C., Li, M., Sun, L., Xue, Z., Wang, J., Feng, J., Yan, F., Zhao, N., Liu, J., Long, W., \& Zhao, L. (2014). A gut microbiotatargeted dietary intervention for amelioration of chronic inflammation underlying metabolic syndrome. FEMS Microbiol Ecol, 87, 357-367.

Yatsunenko, T., Rey, F. E., Manary, M. J., Trehan, I., Dominguez-Bello, M. G., Contreras, M., Magris, M., Hidalgo, G., Baldassano, R. N., Anokhin, A. P., Heath, A. C., Warner, B., Reeder, J., Kuczynski, J., Caporaso, J. G., Lozupone, C. A., Lauber, C., Clemente, J. C., Knights, D., Knight, R., \& Gordon, J. I. (2012). Human gut microbiome viewed across age and geography. Nature, 486, 222-227.

Ye, E. Q., Chacko, S. A., Chou, E. L., Kugizaki, M., \& Liu, S. (2012). Greater whole-grain intake is associated with lower risk of type 2 diabetes, cardiovascular disease, and weight gain. $J$ Nutr, 142, 13041313.

Ze, X., Duncan, S. H., Louis, P., \& Flint, H. J. (2012). Ruminococcus bromii is a keystone species for the degradation of resistant starch in the human colon. ISME J, 6, 1535-1543.

Zhang-Sun, W., Augusto, L. A., Zhao, L., \& Caroff, M. (2015). Desulfovibrio desulfuricans isolates from the gut of a single individual: structural and biological lipid A characterization. FEBS Lett, 589, 165-171.

Zhang, C., Zhang, M., Wang, S., Han, R., Cao, Y., Hua, W., Mao, Y., Zhang, X., Pang, X., Wei, C., Zhao, G., Chen, Y., \& Zhao, L. (2009). Interactions between gut microbiota, host genetics and diet relevant to development of metabolic syndromes in mice. ISME J, 4, 232-241.

Zhernakova, A., Kurilshikov, A., Bonder, M. J., Tigchelaar, E. F., Schirmer, M., Vatanen, T., Mujagic, Z., Vila, A. V., Falony, G., Vieira-Silva, S., Wang, J., Imhann, F., Brandsma, E., Jankipersadsing, S. A., Joossens, M., Cenit, M. C., Deelen, P., Swertz, M. A., Weersma, R. K., Feskens, E. J., Netea, M. G., Gevers, D., Jonkers, D., Franke, L., Aulchenko, Y. S., Huttenhower, C., Raes, J., Hofker, M. H., Xavier, R. J., Wijmenga, C., \& Fu, J. (2016). Population-based metagenomics analysis reveals markers for gut microbiome composition and diversity. Science, 352, 565-569. 
1094

1095 
Figure 1.The bacterial butyrate synthesis pathways (adapted from (Vital, et al., 2014)). Vital and coworkers have reconstructed four different pathways for butyrate synthesis through and an extensive metagenomic approach. Protein names and major substrates are shown across the different biosynthetic pathways. Genes/proteins responsible of the last step of butyrate production, and frequently used as biomarkers for gut microbiota studies, are highlighted in red. They are known as: 4Hbt, butyryl-CoA:4hydroxybutyrate CoA transferase; But, butyryl-CoA:acetate CoA transferase; Ato, butyryl-CoA:acetoacetate CoA transferase ( $\alpha, \beta$ subunits); 


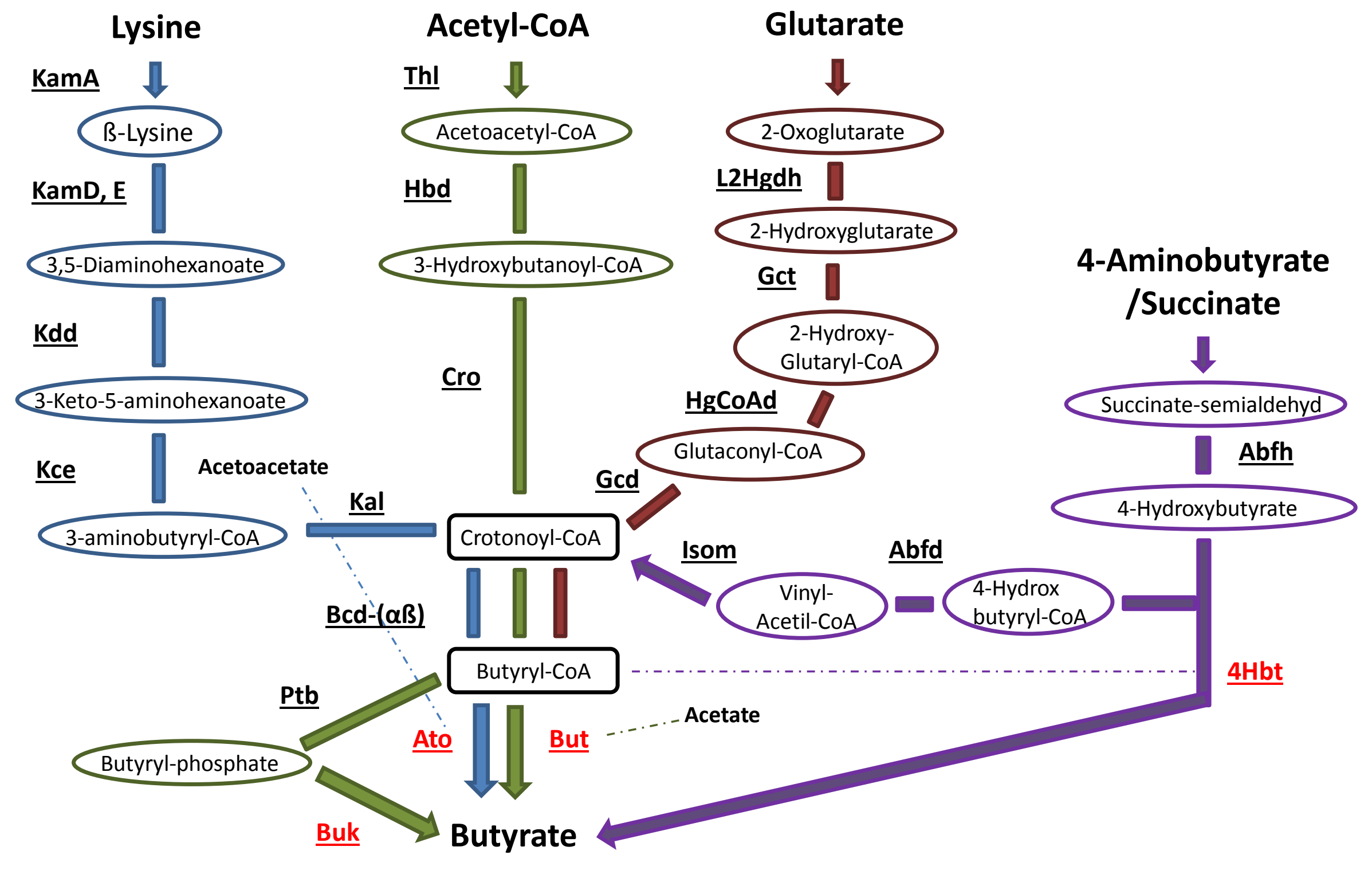


Table 1. Summary of dietary fiber interventional studies with gut microbiota assessments in humans.

\begin{tabular}{|c|c|c|c|c|c|c|c|}
\hline Fiber & Study Design & Subjects & Time & Gender & Population & Effects on gut microbiota $^{1}$ & Reference \\
\hline $\begin{array}{l}\text { Maize-derived } \\
\text { WG cereal }\end{array}$ & $\mathrm{DB}, \mathrm{R}, \mathrm{PC}, \mathrm{CO}$ & 32 & 3 weeks & $\begin{array}{l}\text { Females (21) } \\
\text { Males (11) }\end{array}$ & $\begin{array}{l}\text { European } \\
\text { UK }\end{array}$ & $\uparrow$ Bifidobacterium & (Carvalho-Wells, et al., 2010) \\
\hline WG wheat cereal & $\mathrm{DB}, \mathrm{R}, \mathrm{PC}, \mathrm{CO}$ & 31 & 3 weeks & $\begin{array}{l}\text { Females (16) } \\
\text { Males (15) }\end{array}$ & $\begin{array}{l}\text { European } \\
\text { UK }\end{array}$ & $\uparrow$ Bifidobacterium, Lactobacillus & (Costabile, et al., 2008) \\
\hline WG barley & $\mathrm{R}, \mathrm{CO}$ & 28 & 4 weeks & $\begin{array}{l}\text { Females (17) } \\
\text { Males (11) }\end{array}$ & USA & $\begin{array}{l}\uparrow \text { Blautia,Bifidobacterium, Roseburia, } \\
\text { Dialister } \\
\leftrightarrow \text { Dialister- plasma IL-6levels } \\
\leftrightarrow \text { Eubacterium- plasmaglucose/insulin }\end{array}$ & (Martinez, et al., 2013) \\
\hline Inulin & $\mathrm{DB}, \mathrm{R}, \mathrm{PC}, \mathrm{CO}$ & 32 & 4 weeks & Females & $\begin{array}{l}\text { European } \\
\text { Switzerland }\end{array}$ & $\uparrow$ Bifidobacterium & (Petry, et al., 2012) \\
\hline Inulin (Agave) & $\mathrm{DB}, \mathrm{R}, \mathrm{PC}, \mathrm{CO}$ & 29 & 3 weeks & NA & USA & $\begin{array}{l}\uparrow \text { Bifidobacterium } \\
\downarrow \text { Desulfovibrio } \\
\leftrightarrow \text { Faecalibacterium - fecal butyrate }\end{array}$ & (Holscher, et al., 2015) \\
\hline Inulin / FOS & DB, R, PC & 31 & 8 weeks & Females & $\begin{array}{l}\text { European } \\
\text { Spain }\end{array}$ & $\uparrow$ Bifidobacterium, Lactobacillus & (Garcia-Peris, et al., 2012) \\
\hline $\begin{array}{l}\text { Inulin-type } \\
\text { fructans }\end{array}$ & $\mathrm{DB}, \mathrm{R}, \mathrm{PC}$ & 30 & 12 weeks & Females & $\begin{array}{c}\text { European } \\
\text { Belgium }\end{array}$ & $\begin{array}{l}\uparrow \text { Bifidobacterium, } \\
\text { Faecalibacteriumprausnitzii } \\
\downarrow \text { Bacteroides, Propionibacterium } \\
\leftrightarrow \text { Bifidobacterium - plasma LPS levels } \\
\leftrightarrow \text { Faecailbacterium - plasma LPS levels } \\
\leftrightarrow \text { Bacteroides - Fat mass }\end{array}$ & (Salazar, et al., 2015) \\
\hline $\begin{array}{l}\text { Inulin / } \\
\text { Oligofructose }\end{array}$ & $\mathrm{DB}, \mathrm{R}, \mathrm{PC}$ & 22 & $\begin{array}{l}12 \text { days } \\
\text { (mean) }\end{array}$ & $\begin{array}{l}\text { Females (9) } \\
\text { Males (13) }\end{array}$ & $\begin{array}{l}\text { European } \\
\text { UK }\end{array}$ & $\downarrow$ Faecalibacterium, Bacteroides, Prevotella & (Majid, et al., 2014) \\
\hline $\begin{array}{l}\text { Inulin / } \\
\text { Oligofructose }\end{array}$ & $\mathrm{DB}, \mathrm{PC}$ & 30 & 12 weeks & Females (44) & $\begin{array}{l}\text { European } \\
\text { Belgium }\end{array}$ & $\begin{array}{l}\uparrow \text { Bifidobacterium, } \\
\text { Faecalibacteriumprausnitzii }\end{array}$ & (Dewulf, et al., 2013) \\
\hline $\begin{array}{l}\text { Inulin / } \\
\text { Oligofructose }\end{array}$ & $\mathrm{DB}, \mathrm{R}, \mathrm{PC}$ & 252 & 16weeks & $\begin{array}{l}\text { Females (123) } \\
\text { Males (129) }\end{array}$ & $\begin{array}{l}\text { European } \\
\text { Spain }\end{array}$ & $\uparrow$ Bifidobacterium & (Closa-Monasterolo, et al., 2013) \\
\hline B-GOS & $\mathrm{DB}, \mathrm{R}, \mathrm{PC}, \mathrm{CO}$ & 45 & 6 weeks & $\begin{array}{l}\text { Females (29) } \\
\text { Males (16) }\end{array}$ & $\begin{array}{l}\text { European } \\
\text { UK }\end{array}$ & $\begin{array}{l}\uparrow \text { Bifidobacterium } \\
\downarrow \text { Clostridium histolyticum, Desulfovibrio, } \\
\text { Bacteroides }\end{array}$ & (Vulevic, et al., 2013) \\
\hline GOS & DB, R, PC, CO & 31 & 3 weeks & Females & $\begin{array}{l}\text { European } \\
\text { The Netherlands }\end{array}$ & $\uparrow$ Bifidobacterium & (Whisner, et al., 2013) \\
\hline GOS & $\mathrm{DB}, \mathrm{R}, \mathrm{PC}$ & 163 & $>16$ weeks & NA & $\begin{array}{l}\text { European } \\
\text { Italy }\end{array}$ & $\uparrow$ Bifidobacterium & (Giovannini, et al., 2014) \\
\hline XOS & R, PC & 22 & 3 weeks & $\begin{array}{l}\text { Females (7) } \\
\text { Males (15) }\end{array}$ & Taiwan & $\uparrow$ Bifidobacterium & (Chung, et al., 2007) \\
\hline AXOS & $\mathrm{R}, \mathrm{PC}, \mathrm{CO}$ & 20 & 3 weeks & $\begin{array}{l}\text { Females (14) } \\
\text { Males (6) }\end{array}$ & $\begin{array}{l}\text { European } \\
\text { Belgium }\end{array}$ & $\uparrow$ Bifidobacterium & (Cloetens, et al., 2010) \\
\hline AXOS & DB, R, PC, CO & 63 & 3 weeks & $\begin{array}{l}\text { Females (30) } \\
\text { Males (33) }\end{array}$ & $\begin{array}{c}\text { European } \\
\text { Belgium }\end{array}$ & $\uparrow$ Bifidobacterium & (Francois, et al., 2012) \\
\hline AXOS & DB, R, PC, CO & 65 & 3 weeks & $\begin{array}{l}\text { Females (35) } \\
\text { Males (30) }\end{array}$ & USA & $\uparrow$ Bifidobacterium & (Maki, et al., 2012) \\
\hline RS3 & $\mathrm{R}, \mathrm{CO}$ & 14 & 3 weeks & NA & $\begin{array}{l}\text { European } \\
\text { Scotland } \\
\end{array}$ & $\uparrow$ Ruminococcusbromii, Eubacteriumrectale & (Walker, et al., 2011) \\
\hline
\end{tabular}




\begin{tabular}{|c|c|c|c|c|c|c|c|}
\hline RS2, RS4 & $\mathrm{DB}, \mathrm{CO}$ & 10 & 3 weeks & $\begin{array}{c}\text { Females (5) } \\
\text { Males (5) }\end{array}$ & USA & $\begin{array}{l}\uparrow \text { Bifidobacterium adolescentis, } \\
\text { Eubacteriumrectale, Ruminococcusbromii, } \\
\text { Parabacteroides distasonis } \\
\downarrow \text { Faecalibacteriumprautsnitzii, } \\
\text { Doreaformicigenerans }\end{array}$ & (Martinez, et al., 2010) \\
\hline RS & $\mathrm{R}, \mathrm{CO}$ & 46 & 4 weeks & $\begin{array}{c}\text { Females (30) } \\
\text { Males (16) }\end{array}$ & Australia & $\uparrow$ Ruminococcusbromii & (Abell, et al., 2008) \\
\hline
\end{tabular}

1 Gut microbiota changes expressed in terms of abundance. $\uparrow$ indicates higher proportions of a determined bacterial genus after intervention, and $\downarrow$ indicates the inverse effect. $\leftrightarrow$ indicates direct correlations among bacterial abundance and metabolic parameters studied, being negative or positive, respectively.DB= Doubleblind; Single-Blind $=\mathrm{SB} ; \mathrm{R}=$ randomized; $\mathrm{PC}=$ Placebo-controlled; $\mathrm{CO}=$ Cross-over; $\mathrm{NA}=$ No information was explicitly available for gender distribution into the intervention groups. 